\title{
LA UNIÓN EUROPEA COMO SUJETO JURÍDICO INTERNACIONAL SINGULAR EN LA GOBERNANZA ÁRTICA
}

\author{
MARTA SOBRIDO PRIETO' \\ marta.sobrido@udc.es
}

\author{
Cómo citar/Citation \\ Sobrido Prieto, M. (2017). \\ La Unión Europea como sujeto jurídico internacional \\ singular en la gobernanza ártica. \\ Revista de Derecho Comunitario Europeo, 57, 473-516. \\ doi: https://doi.org/10.18042/cepc/rdce.57.03
}

\section{Resumen}

Desde los años noventa el Ártico está vinculado, inevitable y progresivamente, al cambio climático, que provoca en esta región una gran preocupación medioambiental e importantes expectativas de explotación económica. La especial vulnerabilidad del Ártico, hasta ahora protegido de la explotación humana por su difícil accesibilidad y habitabilidad, se empieza a ver comprometida no solo por la progresiva accesibilidad que procura el derretimiento de los hielos árticos, sino, sobre todo, por su probable rentabilidad. La inquietud de este nuevo escenario aconseja una protección jurídica

1 Profesora titular de Derecho Internacional Público. Universidad de A Coruña, Instituto Universitario de Estudios Europeos Salvador de Madariaga. Trabajo realizado en el marco del programa de movilidad «Estancias de profesores e investigadores sénior en centros extranjeros» del Ministerio de Educación, Cultura y Deporte (ref. PRX1600428), y en el marco del proyecto "Proceso de negociación internacional para la conservación de la biodiversidad marina en las aguas más allá de la jurisdicción de los Estados» del MINECO (ref. DER2016-78979-R). La autora quiere agradecer todas las facilidades y orientaciones brindadas por el K.G. Jebsen Centre for the Law of the Sea de la UIT, The Arctic University of Norway (Tromsø, Noruega) durante su estancia; especialmente a su director, Tore Henriksen, y a los profesores Elise Johansen, María M. das Neves, y Martin Hennig. 
reforzada, y aunque la estrategia internacional que seguir provocó cierto debate en un primer momento, actualmente la aproximación es sectorial y multinivel. La participación de la UE en este proceso es desigual, ya que varía según el foro, y es asimétrica, porque no siempre se corresponde con las competencias que le han atribuido sus Estados miembros. Los desafíos a los que, con carácter general, se enfrenta la Unión para ser admitida en la comunidad jurídica internacional, se manifiestan claramente en este ámbito. Respecto a la gobernanza ártica, la Unión no es propiamente un foro (como es, por ejemplo, el Consejo Ártico) sino un actor (como lo son los Estados, árticos y no árticos). No obstante, el hecho de ser una organización internacional y, además, convivir frecuentemente con sus propios miembros —algunos de ellos árticos - en los mismos foros en los que se abordan temas de trascendencia para la región ártica, no facilita la aceptación de la UE como actor ártico. Los avances que con carácter general puedan producirse en relación con la aceptación de la UE en la comunidad jurídica internacional, y el fortalecimiento de un Ártico europeo con características propias, podrán ser elementos a su favor.

\section{Palabras clave}

Unión Europea; personalidad jurídica internacional; Ártico; Ártico europeo; cambio climático; gobernanza ártica; Espacio Económico Europeo; Consejo Ártico.

\section{THE EU AS A SINGULAR INTERNATIONAL LEGAL SUBJECT IN ARCTIC GOVERNANCE}

\section{Abstract}

Since the 1990s, the Arctic has been inevitably and progressively linked to climate change, causing great environmental concern and high expectations of economic exploitation. Until very recently, the special vulnerability of the Arctic has been protected from human exploitation because of its difficult access and habitability. Now this vulnerability is beginning to be compromised not only by its progressive accessibility as a consequence of the Arctic ice melt, but particularly by its probable profitability. Concern about this new scenario calls for enhanced legal protection, and although the international strategy to be followed led to some debate at first, the approach about Arctic governance is now sectoral and multileveled. As a result, the EU presence in that process is unequal (different according to the forum) and asymmetrical (it does not always correspond to the competences conferred by the states to the EU). In this area, the challenges that generally face the EU in terms of admission to the international legal community, show clearly. With respect to Arctic governance, the EU is not a forum (such as the Arctic Council) but an actor (as are States, Arctic and non-Arctic). However, being an International Organization and frequently coexist with its own Members — some of them Arctic - in the same forums where Arctic issues are addressed, do not facilitate its acceptance as an Arctic 
actor. The progress that may take place in relation to the acceptance of the EU in the international legal community, and the strengthening of a European Arctic with its own characteristics, may be elements in its favour.

\section{Keywords}

European Union; international legal personality; Arctic; European Arctic; climate change; Arctic governance; European Economic Area; Arctic Council.

\section{L'UE EN TANT QUE SUJET JURIDIQUE INTERNATIONAL SINGULIER DANS LA GOUVERNANCE ARCTIQUE}

\section{Résumé}

Depuis les années nonante l'Arctique est progressivement lié au changement climatique, qui suscite dans cette région des préoccupations considérables et des attentes importantes de l'exploitation économique. La vulnérabilité particulière de l'Arctique, jusqu'à présent protégé contre l'exploitation humaine par leurs difficultés en matière d'accessibilité et d'habitabilité, commence à être menacée non seulement par sa accessibilité progressive en raison de la fonte des glaces, mais surtout par sa rentabilité probable. Le souci de ce nouveau scénario recommande une protection juridique renforcée. Le choix de la stratégie internationale à suivre a provoqué un débat au début, mais maintenant l'approche est multi-niveaux et sectorielle. En conséquence, la présence de l'UE est inégale (différent en fonction du forum) et asymétrique (ne correspond pas toujours aux pouvoirs conférés par les Etats de l'UE). Les défis qui, en général, l'Union doit faire face pour être admis à la communauté juridique internationale, sont très claires dans ce domaine. En ce qui concerne la gouvernance de l'Arctique, l'UE n'est pas un forum (comme le Conseil de l'Arctique ...), mais un acteur (comme les États, arctiques et non arctiques). Cependant, le fait d'être une organisation internationale, et le fait de coexister souvent avec ses propres membres, certains d'entre eux arctiques, dans les mêmes forums où sont abordées les questions arctiques, ne facilite pas l'acceptation de l'UE. Les développements qui peuvent avoir par rapport à l'acceptation de l'UE dans la communauté juridique internationale et le renforcement d'un Arctique européen avec ses propres caractéristiques, peuvent être des éléments favorables.

\section{Mots clés}

Union Européenne; personnalité juridique internationale; Arctique; Arctique européen; changement climatique; gouvernance de l'Arctique; Espace économique européen; Conseil de l'Arctique. 
I. INTRODUCCIÓN. II. LA COOPERACIÓN INTERNACIONAL EN ASUNTOS ÁRTICOS. 1. Cooperación sectorial y multinivel. 2. Representación desigual y asimétrica de los intereses de la Unión. III. LA UE Y LA CONSTRUCCIÓN DE UN ÁRTICO EUROPEO. 1. El Ártico europeo. 2. El Espacio económico europeo. IV. CONSIDERACIONES FINALES.

\section{INTRODUCCIÓN}

Para conocer la política para el Ártico de la Unión Europea (en adelante UE, o simplemente Unión), una referencia fundamental y habitual son las comunicaciones adoptadas al respecto por la Comisión Europea, a título individual $y$, tras la entrada en vigor del Tratado de Lisboa, conjuntamente con la alta representante de la Unión para Asuntos Exteriores y Política de Seguridad (en adelante alta representante). Estas comunicaciones son documentos políticos que recogen la orientación de la Unión en este ámbito, y se dirigen a dos instituciones con competencias legislativas, Parlamento Europeo (en adelante PE) y Consejo de la Unión, invitándoles a expresar su punto de vista. Además, el Comité Económico y Social y el Comité de las Regiones, órganos consultivos y también con competencia para emitir dictámenes de propia iniciativa, han adoptado posiciones al respecto. Se trata de un proceso iniciado hace casi diez años, y que no arranca cuando la Unión pasa a tener territorio ártico, puesto que eso sucedió mucho antes (durante 1973-1985, y desde 1995) ${ }^{2}$, ni tampoco cuando la Unión impulsa un plan

2 Durante 1973-1985, Groenlandia formó parte de las entonces Comunidades Europeas; se incorporó en 1973 como parte del territorio danés, pero en 1985, siguiendo los resultados de un referéndum celebrado al efecto en 1982, se retiró de las Comunidades Europeas, aunque siguió formando parte de Dinamarca. En 1995 se adhirieron — además de Austria - Suecia y Finlandia, cuyos territorios septentrionales forman parte de la región ártica. 
de acción específico para sus territorios del norte ${ }^{3}$, que además incluye la cooperación con los Estados vecinos (Dimensión Septentrional, 1999- $)^{4}$. El nacimiento de su política para el Ártico tiene lugar cuando la Unión, al igual que hicieron los propios Estados árticos por esas mismas fechas ${ }^{5}$, identifica el Ártico como una región con entidad propia cuyas circunstancias presentes, y sobre todo futuras, requieren de una estrategia adecuada. Y esta política se encuentra todavía en construcción ${ }^{6}$.

3 Respecto a la situación anterior a la primera comunicación de la Comisión, de 2008 (véase infra nota 7), puede consultarse el informe elaborado a petición del Consejo Nórdico de Ministros sobre las políticas y acciones de la UE que afectan o están relacionadas con el desarrollo en el Ártico. Adele AIROLDI, The European Union and the Arctic. Policies and actions, Nordic Council of Ministers, Copenhagen, 2008. Y sobre la cooperación en la zona, también referido a ese periodo: Pablo PAREJA ALCARAZ, "El Ártico como espacio de cooperación: evolución, contenido y límites», en José Manuel SOBRINO HEREDIA (coord.), Mares y océanos en un mundo en cambio: tendencias juridicas, actores y factores, Tirant lo Blanch, Valencia, 2007, pp. 883-906.

4 Acción conjunta de la UE con Rusia, Noruega e Islandia; se inició en 1999 y se renovó en 2006. Su ámbito geográfico son territorios árticos y subárticos (hacia el oeste alcanza hasta Groenlandia e Islandia; hacia el sur hasta la costa meridional báltica, y hacia el este cubre el noroeste de Rusia). Aunque en el marco de esta Dimensión Septentrional se estableció la llamada "ventana ártica», que dotó de visibilidad específica a la región ártica europea, lo cierto es que, como señala Campins Eritja, el interés político todavía era extremadamente limitado. Mar CAMPINS ERITJA, «The European Union and the North: Towards the Development of an Arctic Policy?», Ocean Yearbook, vol. 27, 2013, pp. 459-485, p. 476.

5 En la página web de «GeoPolitics in the High North» (http://www.geopoliticsnorth. org; sección "Arctic Strategic Documents») pueden consultarse esos primeros documentos adoptados por Noruega (diciembre de 2006), Dinamarca (mayo de 2008, y agosto de 2011), Rusia (septiembre de 2008), Estados Unidos (enero de 2009), Canadá (marzo de 2009 y agosto de 2010), Finlandia (junio de 2010) y Suecia (mayo de 2011). Y sobre el documento adoptado por el parlamento islandés (marzo de 2011), véase: http://arcticiceland.is/en/stefna-islands-i-malefnum-nordhurslodha.

6 Stang llama la atención sobre el hecho de que, frente a la petición del PE de una «estrategia» de la UE para el Ártico, la última Comunicación de 2016 (véase infra nota 7) no se define en ningún momento como tal, sino como una "política integrada». Señala el autor que el escaso tratamiento de asuntos de seguridad y geopolítica impide calificar la Comunicación de 2016 como "estrategia». Gerald STANG, EU Arctic policy in regional context, Parlamento Europeo, 2016, pp. $8-9$. 
Las comunicaciones de la Comisión y la alta representante (2008, 2012, 2016) ${ }^{7}$, y también las correspondientes resoluciones del PE (2008, 2011, 2014, 2017) ${ }^{8}$, conclusiones del Consejo $(2008,2009,2014,2016)^{9}$, y dictámenes del Comité Económico y Social $(2013,2016)^{10}$ y del Comité de las Regiones $(2017)^{11}$, marcan ese proceso de construcción de la política ártica de la Unión pero, por supuesto, no agotan el contenido de dicha política. Todos estos documentos explican, identifican, priorizan, proponen, pero las comunicaciones marcan unas líneas que deben ser concretadas ${ }^{12}$, y las resoluciones/conclusiones/dictámenes recogen la posición de la institu-

7 Comunicación de la Comisión, de 20 de noviembre de 2008, sobre «La Unión Europea y la región ártica», COM (2008) 0763. Comunicación conjunta de la Comisión y la alta representante, de 26 de junio de 2012, titulada «Desarrollo de una política de la Unión Europea para la región del Ártico: avances desde 2008 y próximos pasos», JOIN (2012) 0019. Comunicación conjunta de la Comisión y la alta representante, de 27 de abril de 2016, sobre «Una política integrada de la Unión Europea para el Ártico», JOIN (2016) 0021.

8 Resolución del PE, de 9 de octubre de 2008, sobre la gobernanza del Ártico, DO C 9 E, de 15 de enero de 2010, pp. 41-43. Esta resolución del PE precede en poco más de un mes a la primera comunicación de la Comisión, pero la tiene en cuenta («Vista la Comunicación de la Comisión sobre la política ártica, esperada para el otoño de 2008 [...]»). Resolución del PE, de 20 de enero de 2011, sobre una política sostenible de la UE para el Alto Norte, DO C 136E, de 11 de mayo de 2012, pp. 71-81. Resolución del PE, de 12 de marzo de 2014, sobre la estrategia de la UE para el Ártico; 2013/2595 (RSP). Resolución del PE, de 16 de marzo de 2017, sobre una política integrada de la Unión para el Ártico; 2016/2228 (INI).

9 Conclusiones del Consejo (Asuntos Generales), de 8 de diciembre de 2008, sobre la UE y la región ártica; sesión núm. 2914. Conclusiones del Consejo (Asuntos Exteriores), de 8 de diciembre de 2009, sobre cuestiones árticas; sesión núm. 2985 del Consejo. Conclusiones del Consejo (Asuntos Exteriores), de 12 de mayo de 2014, sobre el desarrollo de una política de la UE para la región del Ártico; ref. ST 9746 2014 INIT. Conclusiones del Consejo (Asuntos Exteriores), de 20 de junio de 2016, sobre el Ártico; ref. ST 104002016 INIT.

10 Dictamen del Comité Económico y Social, de 17 de abril de 2013, sobre «Una política de la UE para la región ártica que dé respuesta a los nuevos desafíos globales en dicha región: una perspectiva de la sociedad civil»; DO C 198, de 10 de julio de 2013, pp. 26-33. Dictamen del Comité económico y Social, de 14 de diciembre de 2016, sobre "Política para la región ártica», ref. REX/470.

11 Dictamen del Comité de las Regiones, de 8 de febrero de 2017, titulado «Una política integrada de la Unión Europea para la región del Ártico»; ref. CDR 4295/2016.

12 Comunicación de 2016, cit., nota 7, p. 19: «Este documento político debe guiar las acciones de la UE en los próximos años [...]. La UE podrá revisar esta política en función de la evolución de los acontecimientos». 
ción/órgano correspondiente. Por ejemplo, no es la UE la que actualmente propone prohibir la perforación en busca de petróleo en las aguas árticas heladas de la Unión y del Espacio Económico Europeo (en adelante EEE), sino el $\mathrm{PE}^{13}$. Por esa razón, y dado que el presente estudio se orienta hacia el papel que desempeña la UE en la gobernanza ártica internacional, tales documentos (las comunicaciones y correspondientes resoluciones, conclusiones y dictámenes) no guiarán nuestro trabajo, aunque sí serán una referencia a lo largo del mismo.

Los actos atribuibles a la Unión que tienen un impacto en la región ártica ${ }^{14}$ son adoptados en un doble plano. Por un lado, actos adoptados en un marco internacional multilateral, donde las competencias de la Unión son representadas directamente por la propia Unión, o a través de sus Estados miembros. Y por otro lado, actos adoptados en el seno de la Unión que no están dando cumplimiento a ningún compromiso internacional, y que son de aplicación en el territorio ártico de la Unión, en el territorio ártico de Noruega e Islandia (en su condición de miembros del EEE), y/o en espacios árticos no sujetos a la soberanía o jurisdicción de ningún Estado (aplicación extraterritorial del derecho de la Unión). Incluso actos cuya aplicación en territorio europeo — de la Unión y/o el EEE — tiene un impacto en territorios árticos no pertenecientes a la UE o al EEE.

Teniendo en cuenta esto, hemos decidido estructurar nuestro trabajo en dos partes claramente diferenciadas.

En la primera parte nos detendremos en el ejercicio de las competencias de la Unión en los foros internacionales en los que se abordan cuestiones de relevancia ártica; entendiendo por foros internacionales, a los efectos del presente trabajo, tanto organizaciones internacionales como foros intergubernamentales y procesos de negociación o, incluso, encuentros internacionales para la discusión y/o concertación de posiciones. En la segunda parte analizaremos en qué medida la UE ha evolucionado hacia la progresiva afirmación de un espacio ártico europeo, del que forman parte, aunque no lo agotan, el territorio de la Unión Europea y el del Espacio Económico Europeo.

13 Resolución del PE de 2017, cit., nota 8, punto 14.

14 Sobre el impacto en materia medioambiental puede consultarse el informe elaborado en 2010 por cuatro instituciones científicas europeas (Ecologic Institute, Alemania; Arctic Centre, Finlandia; Stockholm Environment Institute, Suecia; Sustainable Europe Research Institute, Austria) en el marco de un proyecto financiado por la Comisión Europea que sigue siendo una referencia fundamental. Sandra CAVALIERI et al., The EU Arctic Footprint and Policy Assessment, Ecologic Institute, 2010. 


\section{LA COOPERACIÓN INTERNACIONAL EN ASUNTOS ÁRTICOS}

Desde los años noventa el Ártico está vinculado, inevitable y progresivamente, al cambio climático, que provoca en esta región una gran preocupación medioambiental e importantes expectativas de explotación económica. Una gran preocupación medioambiental por su doble condición de víctima agravada (canario en la mina de carbón) ${ }^{15}$ y, al mismo tiempo, agente acelerador del cambio climático ${ }^{16}$ con efectos de alcance mundial (subida del nivel de mar, acidificación de los océanos, etc.). E importantes expectativas de explotación económica que van desde la navegación y la explotación de recursos naturales vivos (pesca) y no vivos (petróleo, gas, minerales), hasta el turismo. De este modo, la especial vulnerabilidad del Ártico, hasta ahora protegido de la explotación humana por su difícil acceso y habitabilidad, se empieza a ver comprometida no solo por la progresiva accesibilidad que procura el derretimiento de los hielos árticos, sino, sobre todo, por su probable rentabilidad. La inquietud que genera este nuevo escenario aconseja una protección jurídica reforzada, y aunque la determinación de la estrategia internacional que seguir provocó cierto debate en un primer momento, actualmente la aproximación es sectorial y multinivel, produciéndose una presencia desigual y asimétrica de la UE.

15 A los efectos del presente trabajo, y sin ánimo de exhaustividad ni precisión científica, consideramos oportuno destacar que la subida de temperaturas por efecto del calentamiento global provoca en el Ártico un derretimiento de hielos que altera la calidad del agua marina (menor salinidad, mayor temperatura, etc.); y, además, reduce su capacidad reflectante de la luz solar al aumentar la extensión de aguas no cubiertas por hielo, y disminuir el grosor y antigüedad del hielo. Esta especial vulnerabilidad del Ártico explica su reiterada identificación como «canario de la mina de carbón global». Cuando no existía tecnología adecuada para detectar la presencia de gases tóxicos en las minas de carbón, se utilizaban los canarios como «centinelas» por su especial sensibilidad a estos gases; si el canario perdía el conocimiento o moría, era la señal para evacuar urgentemente. Sobre el impacto del cambio climático en el Ártico puede consultarse el informe elaborado en el marco del proyecto ACIA (Arctic Climat Impact Assesment); ACIA, Impacts of a Warming Arctic, Cambridge University Press, 2004, última actualización: 2013. ACIA es un proyecto conjunto del Consejo Ártico y el Comité Internacional de Ciencia Ártica (IASC).

16 Como señalan la Comisión y la alta representante en su Comunicación de 2016 (cit., nota 7, pp. 2-3): «El Ártico está calentándose a un ritmo que casi dobla la media global. Mientras que en el pasado la atención se centraba casi exclusivamente en los efectos del cambio climático sobre el Ártico, recientemente se ha ido cobrando cada vez más conciencia de que los circuitos de realimentación están convirtiendo al propio Ártico en un factor que contribuye al cambio climático». 


\section{COOPERACIÓN SECTORIAL Y MULTINIVEL}

Existen notables diferencias jurídicas entre la excepcional situación jurídica de la Antártida con anterioridad al Tratado Antártico de $1959^{17}$ (espacio no sujeto a la soberanía/jurisdicción indiscutida de ningún Estado), y la ordinaria situación jurídico-territorial del Ártico (espacios sujetos a la soberanía/ jurisdicción de Estados y espacios internacionales; no más controversias territoriales que en otras partes del planeta). Y este contraste se explica, principalmente, por su diferente configuración como espacios terrestre y marítimo: la Antártida es, fundamentalmente, un continente helado; el Ártico es, en su parte más septentrional e inaccesible, un océano helado. No obstante, el excepcional valor medioambiental de ambos espacios propició algunas propuestas $^{18}$ — como la del PE en $2008^{19}$ — de adoptar en relación con el Ártico un

17 También conocido como Tratado de Washington, por ser la ciudad en la que se firmó en 1959, entró en vigor en 1961. Puede consultarse, entre otros, los siguientes trabajos. Christopher C. JOYNER, Governing the Frozen Commons. The Antarctic Regime and Environmental Protection, University of South Carolina Press, 1998; Roser PUIG MARCÓ, Environmental Security and Shipping Safety in Antarctica, en Eva VÁZQUEZ GÓMEZ y Claudia CINELLI (eds.), Regional Strategies to Maritime Security: a Comparative Perspective, Tirant lo Blanch, 2014, pp. 287-311; Adela REY ANEIROS, «La protección del medio ambiente antártico", en Marta SOBRIDO PRIETO (ed.), Espacios polares y cambio climático: desafíos jurídico-internacionales, Tirant lo Blanch, 2017, pp. 211-231; Shirley V. SCOTT, "The Evolving Antarctic Treaty System: Implications of Accommodating Developments in the Law of the Sea», en Erik. J. MOLENAAR, Alex G. OUDE ELFERINK y Donald R. ROTHWELL, The Law of the Sea and the Polar Regions. Interactions between Global and Regional Regimes, Martinus Nijhoff Publishers, 2013, pp. 17-34.

En abril de 2008, Koivurova publicó un trabajo en el que revisaba distintas propuestas realizadas. Tras recordar que una parte de la doctrina no parecía creer probable, aconsejable o necesaria la formalización de la cooperación ártica, este autor explicaba cómo otros autores y organizaciones se habían fijado en el modelo antártico como referente hacia el que podía evolucionar la cooperación ártica. Timo KOIVUROVA, "Alternatives for an Arctic Treaty. Evaluation and a New Proposal», Review of European Community and International Environmental Law, 2008, vol. 17, núm. 1, pp. 14-26.

19 Punto 15 de la Resolución del PE de 2008, cit., nota 8: «Sugiere que la Comisión se prepare para iniciar la apertura de negociaciones internacionales dirigidas a adoptar un tratado internacional para proteger el Ártico, inspirándose en el Tratado Antártico [...] pero respetando la diferencia fundamental del carácter poblado del Ártico y los 
tratado general similar al Tratado Antártico. Esta posibilidad fue firmemente descartada por los cinco Estados ribereños del océano Central Ártico: Estados Unidos, Canadá, Dinamarca, Noruega, y Rusia, frecuentemente identificados como A5. En 2008 estos Estados dejaron clara su posición en la conocida como Declaración de Ilulissat ${ }^{20}$, en la que rechazan la necesidad de desarrollar un nuevo marco jurídico general para el Ártico alegando que el marco jurídico internacional existente - muy especialmente el derecho del mar- también se aplica en el Ártico. Invocando su "posición única» derivada de su condición de Estados ribereños, los A5 afirman que los nuevos retos se pueden abordar con un fortalecimiento y desarrollo del marco ya existente. Y por el momento este ha sido, en efecto, el camino seguido.

Ciertamente existen una serie de tendencias relevantes: persisten campañas de sensibilización de la opinión pública mundial ${ }^{21}$, como la de la organización no gubernamental Greenpeace con su propuesta de un «santuario ártico» en las aguas de alta mar del océano Central Ártico (reclaman la prohibición de actividades extractivas, navegación y actividades militares) ${ }^{22}$; avanza a nivel

consiguientes derechos y necesidades de los pueblos y naciones de la región del Ártico; opina que, como mínimo punto de partida, dicho tratado debería abarcar al menos la zona despoblada y no reivindicada que se encuentra en el centro del Océano Ártico». Esta posición ya no figura en las posteriores resoluciones del PE (2011, 2014, 2017); cit., nota 8 .

20 Declaración presentada en Ilulissat (Groenlandia) el 28 de mayo de 2008 por los cinco Estados ribereños del océano Central Ártico.

21 Sobre la importancia de la opinión pública mundial en su reivindicación de unas instituciones internacionales legítimas y efectivas puede consultarse Armin VON BOGDANDY, Matthias GOLDMANN, Ing VENZKE, «From Public International to International Public Law: Translating World Public Opinion into International Public Authority», European Journal of International Law, vol. 28, núm. 1, 2017, pp. 115-145. Bogdandy et. al. consideran que, ante esta creciente demanda por parte de la opinión pública mundial, es necesario un cambio de paradigma en derecho internacional público. En su trabajo proponen una teoría con la que tratan de identificar, reconstruir y desarrollar el segmento del derecho internacional público que gobierna el ejercicio de la autoridad pública internacional; y una de las cuestiones de la que se ocupan estos autores es del llamado «gobierno por información» (véase pp. 143145), esto es, la posibilidad de influir difundiendo información que ejerza presión o moldee el marco cognitivo de referencia. Los autores toman como ejemplo el ámbito educativo (la influencia de la OCDE a través de sus informes PISA) pero, sin duda, el medioambiental también es un ámbito en el que la información juega un importante papel.

22 Neil T. M. HAMILTON, Arctic Sanctuary. Global Commons, Environmental Protection and Future Proofing, Greenpeace, 2014. 
nacional e internacional la reflexión sobre los derechos de la humanidad ${ }^{23}$, incluida la evolución de la noción de «patrimonio común de la humanidad» ${ }^{24}$; y en el marco de Naciones Unidas se trabaja sobre un posible tratado relativo a la diversidad biológica marina de las zonas situadas fuera de la jurisdicción nacional $^{25}$. Pero al tiempo que sucede todo esto, la protección internacional del Ártico actualmente se refuerza mediante la cooperación sectorial y multinivel.

Cooperación sectorial, en el sentido de no ser omnicomprensiva (la protección del Ártico) sino referida a ámbitos concretos (navegación, pesca, etc.). Y cooperación multinivel porque se articula en el marco de foros de alcan-

23 En junio de 2015, el entonces presidente de Francia, F. Hollande, encargó a C. Lepage, antigua ministra francesa de Medio Ambiente (1995-1997), la elaboración de un informe sobre las diferentes iniciativas a nivel nacional e internacional relativas el reconocimiento de los derechos de la humanidad. El informe, elaborado por un equipo dirigido por Lepage, fue presentado en septiembre de 2015 y contiene una relación de los textos que hasta entonces existían sobre los derechos de la humanidad, y una propuesta de "Declaración de derechos de la humanidad». Corinne LEPAGE (dir.), Déclaration Universelle des Droits de l'humanité. Rapport à l'attention de monsieur le Président de la République, Documentation Française, 2015. Sobre el mismo puede consultarse Philippe WECKEL, «Le rapport Lepage sur les droits de l'humanité et le concept de l'humanité indivisible», Sentinelle, núm. 448, de 11 de octubre de 2015.

Así, Sobrino Heredia en relación con el propio sistema climático. El autor advierte que actualmente una aproximación jurídico-formal a la noción de "patrimonio común de la humanidad» excluye de la misma tanto a los recursos naturales vitales como al propio sistema climático. Pero considera que el sistema climático posee, para la humanidad, una dimensión patrimonial que debe gestionarse en su beneficio. Una gestión que, alega, no debe situarse en la mera cooperación interestatal, sino en el marco de un proceso de institucionalización similar al de la autoridad internacional que rige en relación con la Zona Internacional de Fondos Marinos y Oceánicos. José Manuel SOBRINO HEREDIA, "Cambio climático y Derecho internacional», en SOBRIDO PRIETO, Espacios..., op. cit., nota 17, pp. 27-47, véase pp. 46-47.

25 El 19 de junio de 2015 la Asamblea General de Naciones Unidas aprobó la resolución «Elaboración de un instrumento internacional jurídicamente vinculante en el marco de la Convención de las Naciones Unidas sobre el Derecho del Mar relativo a la conservación y el uso sostenible de la diversidad biológica marina de las zonas situadas fuera de la jurisdicción nacional» (A/RES/69/292). De acuerdo con lo establecido en dicha resolución, se constituyó un comité preparatorio que empezó a trabajar en 2016 y tendrá su última reunión en julio de 2017 . Antes de que concluya el $72^{\circ}$ período de sesiones (2017-2018), y teniendo en cuenta el informe que le presente este comité preparatorio, la Asamblea General adoptará una decisión sobre la convocatoria y fecha de inicio de una conferencia intergubernamental bajo los auspicios de Naciones Unidas para redactar el texto de ese instrumento. 
ce desigual. Alcance universal, como por ejemplo la Organización Marítima Internacional (OMI), organización internacional de la que actualmente son miembros 172 Estados. Alcance regional, como el Consejo Ártico, foro intergubernamental del que son miembros los ocho Estados árticos, que identificaremos como A8 (Estados Unidos, Canadá, Dinamarca, Islandia, Noruega, Suecia, Finlandia, Rusia). Alcance subregional, como por ejemplo el proceso de entendimiento entre los A5, que como ya explicamos anteriormente son los Estados ribereños del océano Central Ártico (son los A8 menos Islandia, Suecia y Finlandia) ${ }^{26}$. Hasta el momento, este proceso de entendimiento entre los A5 se ha concretado fundamentalmente en dos declaraciones: la Declaración de Ilulissat (2008) y la Declaración de Oslo (2015) ${ }^{27}$. También subregional es el Consejo Euroártico de Barents, foro de cooperación intergubernamental que cuenta con siete miembros (Comisión Europea y los seis Estados del Ártico europeo: Dinamarca, Islandia, Finlandia, Noruega, Suecia, Rusia). E igualmente subregional desde la perspectiva del Ártico es OSPAR, mecanismo para la protección medioambiental del Atlántico Nordeste que se organiza en cinco regiones - la región I son las aguas árticas europeas- y que cuenta con dieciséis partes ${ }^{28}$. Por tanto, la cooperación internacional sobre cuestiones de trascendencia ártica se produce tanto a nivel universal, como regional y subregional; e incluso también entre actores que no son definidos por criterios exclusivamente geográficos, como sucede con el actual proceso de negociación relativo a la pesca en el océano Central Ártico, que cuenta con diez partes (A5 + UE, Islandia, Japón, Corea ${ }^{29}$, China) ${ }^{30}$.

26 Sobre la relación entre los A5 y el Consejo Ártico, con una visión bastante positiva acerca de la misma, Andreas KUERSTEN, "The Arctic Five Versus the Arctic Council», Arctic Yearbook 2016, 2016, pp. 389-395. Y una visión crítica de los A5, fundamentalmente por la exclusión de Islandia, Egill Thor NIELSSON y Bjarni Már MAGNUSSON, «The Arctic Five Strike Again», The Arctic Journal, de 30 de julio de 2015.

27 A la Declaración de Ilulissat ya nos hemos referido; véase nota 20. La Declaración de Oslo es relativa a la pesca en el océano Central Ártico; sobre la misma, Erik J. MOLENAAR, «The Oslo Declaration on High Seas Fishing in the Central Arctic Ocean», Arctic Yearbook 2015, 2015, pp. 427-31.

28 La UE, doce Estados de la UE (Bélgica, Dinamarca, Finlandia, Francia, Alemania, Irlanda, Holanda, Portugal, España, Suecia, Reino Unido, Luxemburgo), y otros tres Estados (Islandia, Noruega, Suiza).

29 República de Corea; la identificamos simplemente como Corea para una lectura más ágil.

30 Erik J. MOLENAAR, «International Regulation of Central Arctic Ocean Fisheries», en Myron H. NORDQUIST, John NORTON MOORE y Ronán LONG, Chal- 
No nos detendremos en la evolución y detalle de esta cooperación ${ }^{31}$ que, facilitada por el nuevo escenario político internacional ${ }^{32}$ e impulsada por la nueva sensibilidad medioambiental, tiene sus inicios en torno a los años noventa del siglo pasado ${ }^{33}$, pero se construye fundamentalmente en los últimos

lenges of the Changing Arctic: Continental Shelf, Navigation, and Fisheries, Center for Oceans Law and Policy, Brill Nijhoff, 2016, pp. 429-463.

31 Existen numerosos trabajos, también en la doctrina española; entre otros, los siguientes: Joaquín ALCAIDE FERNÁNDEZ y Claudia CINELLI, "La 'cuestión ártica' y el Derecho internacional», Revista Española de Derecho Internacional, vol. 61, núm. 2, 2009, pp. 381-409; CAMPINS ERITJA, op. cit., nota 4; Fanny CASTRO-RIAL GARRONE, «La Unión europea y la seguridad marítima en el ámbito exterior. La cuestión ártica", en Ana Rosa MARTÍN MINGUIJÓN y Remedios MORÁN MARTÍN (coord.), Seguridad, extranjería y otros estudios histórico-jurídicos, Iustel, 2016, pp. 195-212; Claudia CINELLI, El Ártico ante el derecho del mar contemporáneo, Tirant lo Blanch, 2012; Elena CONDE PÉREZ, «Geopolítica del Ártico: el derecho internacional ante los retos del cambio climático en la región", Cursos de derecho internacional y relaciones internacionales de Vitoria-Gasteiz, 2014, pp. 99-160; Ana MANERO SALVADOR, El deshielo del Ártico. Retos para el derecho internacional, Aranzadi, 2011. PAREJA ALCARAZ, op. cit., nota 3; Antonio SÁNCHEZ ANDRÉS, «Rusia y la geoestrategia del Ártico», Análisis del Real Instituto Elcano, núm.63, 2010, pp. 1-7; Belén SÁNCHEZ RAMOS, «La institucionalización de la cooperación en el Ártico: una mirada al Consejo Ártico» (pp. 139-166) y Marta SOBRIDO PRIETO, «La gobernanza del Ártico» (pp. 105-138), en SOBRIDO PRIETO, Espacios..., op. cit., nota 17; VV .AA., Geopolítica del Ártico. Dos visiones complementarias. España-Singapur, Instituto Español de Estudios Estratégicos, Colección Seguridad y Defensa núm.66, Ministerio de Defensa, 2014.

32 Se suele tomar como referencia el discurso del entonces secretario general del Partido Comunista de la Unión Soviética, Mikhail Gorbachev, en la ciudad rusa de Murmansk el 1 de octubre de 1987. Partiendo de una situación de cambio a nivel internacional — «[...] the international situation is still complicated [...]. There has been some change, however, or, at least, change is starting [...]. The substantive and frank East-West dialogue [...] has become a distinguishing feature of contemporary world politics [...]»—, identifica el Ártico como un lugar estratégico — «The Arctic [...] is the place where the Euroasian, North American and Asian Pacific regions meet, where the frontiers come close [...]»— que debería ser un espacio de paz — «The Soviet Union is in favour of a radical lowering of the level of military confrontation in the region. Let the North of the globe, the Arctic, become a zone of peace»— abierto a la cooperacón económica, científica y medioambiental. Puede consultarse el texto íntegro en: https://www.barentsinfo.fi/docs/Gorbachev_speech.pdf .

33 Por lo que se refiere a la cooperación a nivel regional, más allá del acuerdo logrado en los años setenta para la conservación del oso polar entre los A5, la cooperación pro- 
diez años. Pero sí consideramos oportuno citar algunos de sus resultados más tangibles en navegación y pesca, que nos muestran con claridad este carácter sectorial y multinivel al que aludimos.

En materia de navegación, se han logrado avances a nivel regional y universal. A nivel regional se han adoptado dos acuerdos internacionales bajo los auspicios del Consejo Ártico, foro intergubernamental ártico por excelencia, y del que únicamente son miembros los ocho Estados árticos (A8), aunque también existe la figura de observador. El primer acuerdo, adoptado en 2011 y en vigor desde 2013, es sobre búsqueda y salvamento aeronáutico y marino ${ }^{34}$. El segundo acuerdo, adoptado en 2013 y en vigor desde 2016, es sobre contaminación marina por petróleo ${ }^{35}$. Son acuerdos que, aunque no excluyen la cooperación con terceros ${ }^{36}$, se dirigen a los A8; solo ellos son parte en estos tratados. Su mayor mérito parece residir, precisamente, no tanto en las obligaciones que impone sino en su valor simbólico — como éxito del Consejo Ártico ${ }^{37}$ - y en las posibilidades de cooperación regional que abre ${ }^{38}$.

A nivel universal se ha adoptado un código internacional para los buques que operan en aguas polares, conocido como Código Polar ${ }^{39}$, y que impone

piamente dicha se inició en 1991 con la llamada «Estrategia de Protección Medioambiental Ártica» -Arctic Environmental Protection Strategy (AEPS)—, un acuerdo no vinculante al que en 1996 le siguió la constitución del Consejo Ártico.

Acuerdo de Cooperación para la Búsqueda y el Salvamento Aeronáutico y Marítimo en el Ártico; el texto oficial en inglés puede consultarse en la web del Consejo Ártico: http://www.arctic-council.org/.

35 Acuerdo de Cooperación en Materia de Contaminación Marina por Petróleo. Preparación y Respuesta en el Ártico; el texto oficial en inglés puede consultarse en la web del Consejo Ártico, id.

36 Art. 18 del acuerdo sobre búsqueda y salvamento, cit. nota 34; art. 17 del acuerdo sobre contaminación, cit. nota 35 .

37 Hasta fechas recientes, estos fueron los dos únicos tratados internacionales adoptados bajo los auspicios del Consejo Ártico. El 11 de mayo de 2017 se adoptó un tercer acuerdo para el fortalecimiento de la cooperación científica ártica; puede consultarse el texto oficial en inglés en la web del Consejo Ártico, cit. nota 34. Al igual que en los dos anteriores, solo son miembros los A8, pero se contempla la posible colaboración con terceros (art. 17).

38 Para una visión general sobre ambos acuerdos puede consultarse Svein Vigeland ROTTEM, "A Note on the Arctic Council Agreements", Ocean Development and International Law, vol. 46, núm. 1, 2015, pp. 50-59.

39 Acerca del proceso de preparación y adopción del Código Polar y su contenido puede consultarse Jiayu BAI, "The IMO Polar Code: The Emerging Rules of Arctic Shipping Governance», The International Journal of Marine and Coastal Law, vol. 30, núm. 4, 2015, pp. 674-699. 
una serie de condiciones relativas al buque, a la tripulación y al propio desarrollo de la navegación. Fue adoptado por la OMI en 2014 y ha llevado a enmendar los textos existentes en materia de seguridad y contaminación internacional (SOLAS y MARPOL) ${ }^{40}$; y posteriormente también el relativo a los trabajadores del mar (STCW) ${ }^{41}$. Su entrada en vigor es 2017-2018 ${ }^{42}$. Rige para la navegación por aguas polares, y por tanto no solo árticas sino también antárticas. No obstante, dado que las aguas antárticas gozaban - y continua siendo así- de una mayor protección que las árticas, el Código Polar ha supuesto una mayor aportación para las aguas árticas. De hecho, una de las propuestas del $\mathrm{PE}$ relativa a la navegación en aguas árticas es la de promover, en el marco multilateral oportuno, la prohibición de uso y el transporte de fuelóleo pesado que ya existe en las aguas antárticas ${ }^{43}$.

En el ámbito pesquero, el marco fundamental es subregional, y respecto a las aguas árticas de alta mar deben distinguirse dos situaciones diferentes: por un lado, las aguas septentrionales del Atlántico y del Pacífico, en las que existe pesca comercial regulada por una serie de organizaciones y acuerdos regionales de pesca (OROPs/AROPs) ${ }^{44}$; y por otro, las aguas del océano Cen-

40 El Convenio Internacional para la Seguridad de la Vida Humana en el Mar, conocido como SOLAS, fue adoptado en 1974 y entró en vigor en 1980; con posterioridad ha sido enmendado en varias ocasiones. El Convenio Internacional para Prevenir la Contaminación por los Buques, conocido como MARPOL, fue adoptado en 1973 y cuando todavía no había entrado en vigor se adoptó en 1978 un protocolo que absorbió el texto original; el nuevo instrumento entró en vigor en 1983. En 1997 se adoptó un protocolo. A lo largo de los años el convenio MARPOL ha sido objeto de varias actualizaciones.

41 Convenio internacional sobre normas de formación, titulación y guardia para la gente de mar, conocido como STCW. Fue adoptado en 1978 y entró en vigor en 1984; con posterioridad ha sido enmendado en varias ocasiones.

El Código Polar y las enmiendas a SOLAS se adoptaron en noviembre de 2014. Las enmiendas a MARPOL se adoptaron en mayo de 2015. La fecha de entrada en vigor de las enmiendas al Convenio SOLAS y al Convenio MARPOL fue el 1 de enero de 2017. Las enmiendas a STCW se adoptaron en diciembre de 2016 y entrarán en vigor en julio de 2018.

43 Resolución del PE de 2017, cit., nota 8; considerando V, punto 58.

44 Partiendo de una delimitación amplia del Ártico — criterio de la temperatura — que incluya tanto Islandia como las aguas del mar de Bering, y teniendo en cuenta que una parte de las aguas árticas están bajo soberanía o jurisdicción nacional, podemos distinguir —además del océano Central Ártico — otros tres espacios de alta mar en el Ártico conocidos como: Banana Hole (en el mar de Noruega), Loop Hole (en el mar de Barents), y Donut Hole (en el mar de Bering). 
tral Ártico, en las que todavía no existe pesca comercial. Aunque sin entrar en detalle sobre este tema ${ }^{45}$, y avanzando que más adelante presentaremos los diferentes criterios utilizados para la delimitación del Ártico, consideramos útil destacar ahora dos ideas. Una primera idea es el carácter ártico de ciertas aguas atlánticas y pacíficas, en las que existe importante pesca comercial regulada desde hace años en el marco de OROPs/AROPs. No se trata simplemente de una cuestión semántica, sino que es relevante en el debate acerca de una eventual ampliación — hacia el norte- del ámbito geográfico de estas organizaciones y acuerdos, y también en la identificación del nivel subregional ártico, muy especialmente por lo que se refiere al Ártico europeo. Y la segunda idea a destacar es el protagonismo de los A5 en el proceso regulador de la pesca en el océano Central Ártico, apelando a su posición geográfica para reivindicar su preeminencia (Declaración de Oslo, 2015), y marcando las fases (apertura del proceso negociador — actualmente en curso- a UE, Islandia, China, Japón, Corea).

La protección internacional del Ártico se articula mediante la cooperación sectorial y multinivel, y el papel protagonista a nivel regional y subregional — tal y como acabamos de ver en los ámbitos de la navegación y la pesca- lo ostentan los Estados árticos (A8), y fundamentalmente los ribereños del océano Central Ártico (A5) ${ }^{46}$. Un protagonismo que se justifica por su posición geográfica pero

45 Entre otros. Erik J. MOLENAAR, «Arctic Fisheries Management», en MOLENAAR et al., The Law of the Sea..., op. cit., nota 17, pp. 85-111. Marta SOBRIDO PRIETO, "La gestión de los recursos pesqueros árticos de alta mar», en José Manuel SOBRINO HEREDIA (dir.), La toma de decisiones en el ámbito maritimo: su repercusión en la cooperación internacional y la situación de las gentes del mar, Bomarzo, 2016, pp. 279-304. Lily WEIDEMANN, International Governance of the Arctic Marine Environment. With Particular Emphasis on High Seas Fisheries, Springer, 2014.

Alcaide Fernández habla de «aristocracias polares» para referirse a los Estados que ostentan una posición reforzada tanto en la Antártida como en el Ártico. En la Antártida se trataría de las llamadas "partes consultivas» del Tratado Antártico, que disfrutan de un estatuto diferente al de los restantes Estados parte del Tratado Antártico; son partes consultivas los doce Estados signatarios, pero también aquellos Estados que, de acuerdo con lo dispuesto en el Tratado (art. IX-2), demuestren su interés en la Antártida mediante la realización en ella de investigaciones científicas importantes. De los 53 Estados que actualmente son parte del Tratado Antártico, 29 son partes consultivas. Por lo que se refiere al Ártico, la posición privilegiada se reserva a los ocho Estados con territorios en la región, que son los únicos que ostentan la condición de miembros del Consejo Ártico, y muy especialmente los cinco ribereños del océano Central Ártico. La preeminencia en el Ártico está ligada a una circunstancia territorial y no de compromiso o implicación, como sucede en la Antártida; coincidimos con 
que, además, se ve reforzado por el hecho de que algunos de ellos son Estados de mucho peso en la escena internacional. Y en este juego ¿̇cómo se sitúa la UE? Tal y como veremos a continuación, el ejercicio de las competencias de la Unión en relación con los asuntos árticos se articula, internacionalmente, de un modo desigual y asimétrico.

\section{REPRESENTACIÓN DESIGUAL Y ASIMÉTRICA DE LOS INTERESES DE LA UNIÓN}

Los miembros de la Unión participan, en su condición de Estados, en diferentes foros internacionales que abordan asuntos árticos como, entre otros, el Consejo Ártico, la OMI u OSPAR. El Consejo Ártico es el foro intergubernamental ártico por excelencia; más de la tercera parte de sus miembros son Estados de la Unión, y la participación como observadores también es destaca$\mathrm{da}^{47}$. Teniendo en cuenta el citado Código Polar, otra referencia fundamental es la OMI, organización de la que actualmente son parte 172 Estados, entre ellos todos los miembros de la Unión. Y pensando en la propuesta debatida en OSPAR, aunque por el momento sin éxito, de crear un área marina protegida en relación con el hielo ártico de alta mar, observamos que en la misma son parte la UE y quince Estados, doce de ellos miembros de la Unión ${ }^{48}$.

la afirmación del autor de que la aristocracia ártica es más exclusiva que la antártica. Joaquín ALCAIDE FERNANDEZ, «Espacios polares y Derecho internacional», en SOBRIDO PRIETO, Espacios..., op. cit., nota 17, pp. 49-70, véase pp. 65-66, 69-70.

47 Solo los Estados árticos son miembros del Consejo Ártico: tres pertenecen a la UE (Dinamarca, Finlandia, Suecia) y los cuatro restantes no (Estados Unidos, Canadá, Noruega, Islandia). En cuanto a la figura del observador, se admiten Estados, organizaciones intergubernamentales y organizaciones interparlamentarias. Actualmente hay trece Estados que ostentan la condición de observadores, siete de la Unión: desde 1998, Alemania, Holanda, Reino Unido, y Polonia; desde 2000, Francia; desde 2006, España; desde 2013, Italia.

48 Una de las líneas de actuación de OSPAR es la creación de una red de áreas marinas protegidas (AMP) en el Atlántico nordeste, y ha sido pionera en la creación de una red de AMP de alta mar. Aunque la región menos protegida por OSPAR es la ártica, y por el momento ninguna de sus AMP se localiza en aguas árticas de alta mar, es a esta organización a quien se ha dirigido la propuesta de Greenpeace de crear un AMP en relación con el hielo ártico de alta mar (la denominación oficial era en inglés: OSPAR Arctic Ice High Seas MPA). Esta propuesta fue debatida y rechazada por la Comisión OSPAR con ocasión de su reunión de junio de 2016, que tuvo lugar los días 20-24 de junio de 2016 en Tenerife. Puede consultarse el documento resumen, «Proposals on 
En estos foros, y otros no citados, los Estados miembros de la Unión participan como miembros u observadores. No sucede lo mismo, en cambio, en materia de ordenación pesquera, tanto con carácter general como por lo que se refiere a la pesca en aguas árticas. Desconocemos si en algún foro de ordenación pesquera se ha rechazado a la Unión por no ser un Estado, pero desde el momento en que la UE es admitida, la participación de sus Estados no tiene sentido porque solo la UE tiene competencia exclusiva al respecto ${ }^{49}$. La participación de un Estado de la Unión en un foro de ordenación pesquera en el que ya está presente la UE solo tiene lugar si es para representar los intereses de territorios que no forman parte de la Unión; este es el caso de Dinamarca en relación con Groenlandia y las Islas Feroe. De ahí que, por ejemplo, en la OROP relativa a las aguas árticas del Atlántico nordeste (CPANE) ${ }^{50}$ sean parte — además de Islandia, Noruega, y Rusia - la UE y Dinamarca.

Debemos tener en cuenta que la UE no es un Estado, sino una organización internacional, y como tal tiene una personalidad jurídica internacional limitada y relativa, que condiciona la representación internacional de la UE con carácter general ${ }^{51}$, y también en relación con los asuntos árticos:

a) La UE tiene una personalidad jurídica limitada porque solo puede ejercer las competencias que le han sido atribuidas ${ }^{52}$, resultando además que tales competencias pueden ser exclusivas, compartidas o de apoyo ${ }^{53}$. Podrá suceder, por tanto, que en un determinado foro internacional se discuta un tema de relevancia ártica que sea competencia exclusiva de la UE (por ejemplo, la conservación de los recursos biológicos marinos), competencia compartida entre UE y Estados (por ejemplo, transporte o medio ambiente), o de un ám-

the establishment and management of MPAs in ABNJ» (puntos 6.24-6.28). Summary Record, OSPAR 2016, OSPAR 16/20/1-E.

49 Art. 3.d) del TFUE, competencia exclusiva de la Unión en materia de conservación de los recursos biológicos marinos.

50 Comisión de Pesca del Atlántico Nordeste. Sus siglas en español son CPANE, pero también es conocida por sus siglas en inglés: NEAFC.

51 Véase Ricardo GOSALBO BONO, «Insuficiencias jurídicas e institucionales de la acción exterior de la Unión Europea», Revista de Derecho Comunitario Europeo, núm.50, 2015, pp. 231-320, véase pp. 235-241.

52 Art. 5.2 TUE, principio de atribución.

53 Competencias exclusivas (art. 3 TFUE), cuando solo la UE tiene competencia. Competencias compartidas (art. 4 TFUE), cuando tienen competencia ambos -UE y Estados-, pero no de modo concurrente; para actuar, la Unión tiene que justificar la conveniencia de su actuación frente a la estatal (art. 5.3 TUE, principio de subsidiariedad). Competencias de apoyo (art. 6 TFUE), cuando la actuación de la UE apoya, complementa o coordina la acción estatal. 
bito en el que la UE ejerce una competencia de apoyo (por ejemplo, turismo o cultura).

b) La UE tiene una personalidad jurídica relativa, en tanto no objetiva frente a todos los sujetos de derecho internacional, sino solo frente a quien la reconozca expresa o tácitamente. Esto explica que su admisión en los diferentes foros internacionales sea desigual. Por ejemplo, la admisión como un miembro más de la UE en las OROPs — así, en la citada CPANE, que cubre aguas árticas - no se debe solo al hecho de que la UE tenga competencia exclusiva en ese ámbito, sino a la aceptación, por parte de las restantes partes, de la UE como un miembro más. De hecho, en materia aduanera, donde la competencia de la UE también es exclusiva, nos encontramos con que la admisión en la Organización Mundial de Aduanas (OMA) no es posible según la actual versión de su tratado constitutivo.

Dado que la gobernanza internacional del Ártico es sectorial y multinivel, la representación de los intereses árticos de la UE no se articula en un único foro, sino en varios. En este escenario, los condicionantes de la personalidad jurídica internacional de la Unión a los que acabamos de aludir, explican que esta representación sea desigual (diferente según el foro) y asimétrica (no se corresponde con las competencias atribuidas por los Estados a la Unión) ${ }^{54}$. Y por ello en ocasiones son los Estados miembros los que asumen esta representación de los intereses de la Unión.

Los Estados de la Unión participan en foros internacionales ejerciendo competencias propias, pero en ocasiones también representando competencias de la Unión. Esto último sucede cuando se tratan cuestiones que son competencia de la Unión pero el foro en cuestión no admite la participación de la Unión como miembro; por ejemplo, la OMI. En tales casos la UE fija su posición y sus Estados miembros la representan. La inadmisibilidad de la Unión en un foro internacional que en cambio sí admite a sus Estados miembros, no tiene efectos en el reparto competencial de la UE, sino solo en su representación internacional. La inadmisibilidad de la UE no provoca, por sí sola, que las competencias de la UE pasen a ser ejercidas por los Estados miembros (como sí sucede cuando, en el ámbito de las competencias compartidas, la escala de la Unión no aporta respecto a lo que sería la escala nacional) ${ }^{55}$. Lo que provoca la inadmisibilidad es que pasen a ser representadas por los Esta-

54 En relación con el alcance de la personalidad jurídica internacional de la UE, Gosalbo Bono habla de asimetría entre, por un lado, la voluntad de los Estados miembros y, por otro, los terceros países y el derecho internacional. GOSALBO BONO, op. cit., nota 51, p. 241.

55 Principio de subsidiariedad. Art. 5 TUE. 
dos miembros. Visto desde esta perspectiva, podríamos decir que la UE está presente incluso cuando no es visible. Un buen ejemplo, es el Código Polar ${ }^{56}$.

Pero más allá de lo que pueda ser la actuación dentro de la propia UE para conformar la posición que, en su caso, deban representar los Estados miembros en el foro internacional correspondiente, la participación de la UE en tales foros bajo otras fórmulas diferentes a la condición de miembro también es importante ${ }^{57}$. Cuando la UE no es admitida como miembro de un foro internacional en el que se abordan temas árticos que son competencia de la UE es importante que tenga, al menos, algún tipo de participación. Como parte observadora o, incluso, con figuras a medio camino entre la condición de miembro y de observador, como sucede en la OCDE donde, a pesar de no ser actualmente una organización europea sino de alcance universal, la UE goza de una posición única pudiendo formar parte de los trabajos aunque sin derecho a voto ${ }^{58}$.

El estatus - como miembro, observador, categoría intermedia, o sin participación alguna- de la UE en los foros internacionales depende de factores jurídicos y/o políticos, tanto en relación con el foro en cuestión (o algunos de sus miembros), como en relación con la propia UE (o algunos de sus miem-

56 Así, la Decisión del Consejo de la Unión en la que se fija la posición que los Estados miembros de la UE deberán adoptar, en nombre de la UE, en dos comités de la OMI a propósito de la adopción de ciertas enmiendas a los convenios MARPOL y SOLAS. Considerando 5: «Las enmiendas de los anexos I y II del Convenio MARPOL incorporarán medidas asociadas con la adopción del proyecto de [...] Código Polar [...] para convertir este Código en obligatorio». Considerando 8: «La Unión no es miembro de la OMI ni parte contratante de los citados convenios [MARPOL, SOLAS]. Es necesario, por tanto, que el Consejo autorice a los Estados miembros para que expresen la posición a adoptar en nombre de la Unión y para que expresen su consentimiento en quedar obligados por las enmiendas en cuestión, en la medida en que son competencia exclusiva de la Unión». Decisión (UE) 2015/1534 del Consejo; DO L 240, 16-9-2015, pp. 61-63.

57 Como señala Kaddous, la complejidad — interna y externa- que conlleva la participación de la UE en foros internacionales no debería frenar una mayor participación. Christine KADDOUS, «The European Union in International Organisations. Functional Necessity or General Aspiration?», en Christine KADDOUS, The European Union in International Organisations and Global Governance: Recent Developments, Bloomsbury Publishing, 2015, pp. 1-22, p. 22.

58 Organización para la Cooperación y el Desarrollo Económicos (OCDE) establecida en 1961 y de la que son parte 35 Estados de Europa, América, Asia y Oceanía. La participación de la UE —entonces Comunidades Europeas- aparece recogida en el Protocolo núm.1 al Convenio de la OCDE (1960). 
bros $)^{59}$. Factores jurídicos y políticos que, con frecuencia, se entremezclan; muy especialmente porque la remoción de los obstáculos jurídicos no suele depender de una instancia judicial, sino de la conformidad de los miembros actuales $^{60}$. Aunque a veces los factores que obstaculizan la participación de la UE son únicamente políticos; y desafortunadamente un claro ejemplo es, precisamente, el foro ártico por excelencia, el Consejo Ártico, donde la UE lleva casi diez años esperando a que se le reconozca la condición de observador permanente.

La UE solicitó ser observadora del Consejo Ártico en 2008, pero cuando debía pronunciarse sobre ello este acordó posponer su decisión (cumbre ministerial bianual celebrada en Kiruna, Suecia, en mayo de 2013 ${ }^{61}$. El problema fue el malestar canadiense ante una determinada regulación europea relati-

59 Factores jurídicos: relativos al foro en cuestión (condiciones requeridas para la admisión como miembro y/o observador); o a la UE (atribución competencial). Factores políticos: relativos al foro en cuestión (por ejemplo, recelo ante un excesivo protagonismo de la UE); relativos a algunos miembros de ese foro (tensión entre la UE y algún/os miembros de ese foro por razones ajenas a tal foro); relativos a la UE (por ejemplo, interés que despierta ese foro dentro de la UE); relativos a ciertos miembros de la UE (por ejemplo, interés de ciertos Estados miembros de la UE en mantener un identidad propia dentro de ese foro).

Pensemos, por ejemplo, en la ya citada OMA, y recordemos que una de las competencias exclusivas de la UE es, precisamente, la unión aduanera. La UE no es miembro de la OMA, pero desde hace diez años goza de un estatus similar a la membresía. En 2007 el Consejo de la OMA aceptó la solicitud de la UE, pero para su plena incorporación es necesario reformar la convención y dicha reforma —una enmienda que permita la incorporación a la OMA de otras organizaciones económicas y aduaneras - debe ser ratificada por los actuales miembros. Mientras eso no sucede, la UE tiene una situación provisional (en la propia web institucional se incluye a la UE en el listado de miembros con la nota: «status akin to membership»).

61 Señala Wegge que en la cumbre de 2011 (Tromsø, Noruega) el argumento oficial fue no admitir nuevos observadores — ni la UE ni ningún otro- para poder reflexionar sobre el papel de los observadores, pero la razón de fondo era la oposición a la UE por la regulación europea relativa a los productos derivados de las focas; véase infra nota 62. Njord WEGGE, «The EU and the Arctic: European foreign policy in the making», Arctic Review on Law and Politics, vol. 3, núm. 1, 2012, pp. 6-29, p. 20. En la cumbre de 2013 (Kiruna) se admitió a otros observadores, y respecto a la UE se decidió que: «El Consejo Ártico acepta la solicitud de la UE para obtener estatuto de observador, pero aplaza la adopción de una decisión definitiva sobre su aplicación hasta que sean resueltas las preocupaciones de los miembros del Consejo abordadas por el Presidente de la Comisión Europea en su carta de 8 de mayo, sin perjuicio de que la UE pueda asistir como observadora a los trabajos del Consejo hasta que este actúe 
va a los productos derivados de las focas, actualmente resuelto ${ }^{62}$. La acusación contra la Unión de insensibilidad con los pueblos indígenas — que ya había provocado tensiones en el pasado ${ }^{63}$ - era fácil de vender en el contexto ártico. En realidad, cuando la UE aprobó en 2009 el reglamento de los productos derivados de las focas lo hizo sin que sus Estados árticos, que representan más de un tercio de los miembros del Consejo Ártico, se opusieran verdaderamente ${ }^{64}$;

en relación con la propuesta contenida en la carta» (Comunicación de la Comisión de 2016, cit., nota 7, véase nota 34).

62 En noviembre de 2009, Canadá (asunto DS401) y Noruega (asunto DS401) presentaron sendas reclamaciones ante la Organización Mundial del Comercio (OMC) contra la UE, entonces Comunidad Europea, en relación con las medidas europeas que prohibían la importación y comercialización de productos derivados de las focas (Reglamento CE 1007/2009 y medidas conexas). Noruega se sumó a las consultas del asunto iniciado por Canadá, y viceversa, e Islandia se sumó a las consultas de ambos asuntos. Tras pasar por diferentes fases (Grupo Especial, Órgano de Apelación), ambos procesos concluyeron finalmente en 2014 con la adopción por parte del Órgano de Solución de Diferencias (OSD) de la OMC de una serie de recomendaciones y resoluciones. A continuación, la UE informó de su intención de aplicar tales medidas. En 2015 el citado Reglamento CE 1007/2009 fue modificado mediante el Reglamento UE 2015/1775 del PE y del Consejo (DO L 262, de 7 de octubre de 2015, pp. 1-6).

63 Como señala Campins Eritja, ya antes de la polémica relativa a la comercialización de productos derivados de las focas, se planteó el problema de importación de pieles de animales cazados con cepos por parte de cazadores canadienses y rusos. En 1991, la entonces Comunidad Económica Europea prohibió la importación de pieles y productos manufacturados de determinadas especies animales salvajes originarias de países que utilizaban para su captura cepos o métodos no conformes a las normas internacionales de captura no cruel (Reglamento CEE 3254/91 del Consejo, DO L 308, de 9 de noviembre de 1991). La celebración en 1998 de un acuerdo entre la entonces Comunidad Europea, Canadá y Rusia sobre normas internacionales de captura no cruel (DO L 42, de 14 de febrero de 1998, pp. 43-57) permitió la importación de pieles de estos países. CAMPINS ERITJA, op. cit., nota 4, p. 483.

64 Tras el acuerdo alcanzado en primera lectura con el PE, el Consejo adoptó el Reglamento. Durante el proceso los tres Estados árticos realizaron declaraciones: Dinamarca manifestó sus dudas sobre la utilidad de esta regulación y su temor a que pudiese afectar negativamente a los cazadores de Groenlandia, mientras Suecia y Finlandia (y Estonia) expresaron su preocupación por los efectos negativos que esta regulación pudiera tener con importantes socios comerciales (véase doc. 11152/09 ADD 1 de la Secretaria General del Consejo, de 20 de julio de 2009). Finalmente la decisión fue adoptada sin discusión y solo Dinamarca (junto con Rumanía y Austria) se abstuvieron (véase comunicado de prensa 12370/09, relativo al Consejo de Asuntos Generales de 27 de julio de 2009). 
pero era, indudablemente, un tema ligado de manera directa a los pueblos indígenas árticos ${ }^{65}$.

Este problema de la regulación europea de los productos derivados de las focas está resuelto desde 2014, y posteriormente se han celebrado dos nuevas cumbres. Una en abril de 2015 (Iqualuit, Canadá), cuando sobre la UE ya no pesaba el veto canadiense pero sí la oposición rusa ${ }^{66}$, y no se admitieron nuevos observadores. Y otra en mayo de 2017 (Fairbanks, Estados Unidos), reunión en la que se han admitido nuevos observadores, pero la Unión no está entre ellos. Las sanciones de la UE a Rusia como consecuencia de la crisis de Ucrania no facilitan la posición de la Unión. En realidad, otros Estados árticos participan también en estas sanciones ${ }^{67}$, y no está conectado con una problemática genuinamente ártica, aunque sí tiene importantes consecuencias económicas en el Ártico ${ }^{68}$.

65 En su «Estrategia para el Ártico 2011-2020», lanzada en 2011, el Gobierno danés afirmaba: "We must seek to avoid further cases where the laws, traditions, cultures and needs of Arctic societies are neglected, as for example in the EU's ban on the import of seal products». Kingdom's strategy for the Arctic 2011-2020, Ministry of Foreign Affairs (Denmark), 2011.

66 Fernando GARCÉS DE LOS FAYOS, "The outcome of the ninth Arctic Council ministerial meeting», Parlamento Europeo, 2015, ref. DG XPO/B/PolDep/ Note/2015_171.

67 En ese sentido son especialmente interesantes las declaraciones de B. Brende, el entonces - y actual - ministro de Asuntos Exteriores de Noruega, insistiendo en la convivencia, al mismo tiempo, de sanciones y cooperación práctica con Rusia: «[...] the Arctic cannot be viewed in isolation from events elsewhere. Russia's violations of international law in Ukraine have had a negative impact on our relations. In response to these violations, Norway, like the EU and the US, has implemented restrictive measures against Russia, suspended our military cooperation and postponed a number of political contacts. Our message is clear: we will not accept Russia's illegal actions. However, our message is also clear regarding the necessity of cooperation with our neighbor Russia in certain areas of common interest [...] practical cooperation in the north does not contradict our principled reaction to Russia's violations of international law, where we are fully in line with our allies in NATO and partners in the EU» (Børge BRENDE, "The Arctic: Important for Norway, Important for the world», Harvard International Review, de 16 de julio de 2015).

La imposición de sanciones a Rusia en 2014 limitó su acceso a la tecnología marina, provocando la suspensión de perforaciones de petróleo y gas en aguas árticas rusas. En 2017 la compañía rusa Gazprom se ha propuesto reanudar las perforaciones en el mar de Kara, y así se anuncia una licitación relativa a una plataforma y servicios de suministro para la perforación del campo de gas de Leningradskaya (Thomas NILSEN, 
En definitiva, en relación con el principal foro regional ártico, la UE lleva esperando casi diez años por el reconocimiento de una situación no principal (no solicita la admisión como miembro sino como observadora), para la que no hay obstáculo legal, y de la que, de hecho, gozan muchas otras organizaciones ${ }^{69}$. Una situación que, además, lleva desarrollando de facto — como observadora ad hoc - desde hace años.

\section{LA UE Y LA CONSTRUCCIÓN DE UN ÁRTICO EUROPEO}

Con carácter general, la UE se enfrenta a grandes desafíos en materia de acción exterior: el debilitamiento de su influencia internacional en los últimos tiempos $^{70}$, las dificultades que entraña su condición de organización internacional ${ }^{71}$, su especificidad como organización internacional ${ }^{72}$, y los propios retos que se plantean desde la perspectiva interna de la propia Unión ${ }^{73}$. Todo

"Gazprom to resume Kara Sea drilling», The Independent Barents Observer, de 2 de febrero de 2017).

69 Desde 2013 cuenta con 32 observadores (doce Estados; nueve organizaciones intergubernamentales e interparlamentarias; once ONGs). En la cumbre de mayo de 2017 se han admitido siete nuevos observadores (Suiza y seis organizaciones).

$70 \mathrm{Al}$ respecto, señala Barbé Izuel que «tanto en el terreno del poder material como en el de las ideas, el mundo es más adverso para la UE de lo que era hace unos años». Esther BARBÉ IZUEL, «Introducción: cambio en el sistema internacional, adversidad para la UE», Revista CIDOB d'Afers Internacionals, núm.108, 2014, pp. 7-21, p. 10.

71 Como señala Roldán Barbero (p. 480): «[...] aparte de enemigos y obstáculos internos, el Derecho internacional opone resistencia a la plena integración en su comunidad jurídica de un sujeto atípico como es la UE». Javier ROLDÁN BARBERO, «La aplicación territorial del derecho de la Unión Europea y el derecho internacional», Revista de Derecho Comunitario Europeo, núm. 51, 2015, pp. 453-490, véase pp. 457 458, 483.

72 Así, José MARTÍN Y PÉREZ DE NANCLARES, «La posición de los Estados miembros ante la evolución de la Unión Europea: comprometidos con el proceso de integración, convencidos de la necesidad de reforzar los rasgos de intergubernamentalidad», Revista de Derecho Comunitario Europeo, núm.50, 2015, pp. 125-171; sobre el carácter sui generis de la Unión, pp. 132-134.

73 Así, el reto de la coherencia entre las distintas políticas de la Unión (coherencia horizontal) y entre la UE y los Estados miembros (coherencia vertical). Sobre la coherencia: Marise CREMONA, "Coherence in European Union Foreign Relations Law», en Panos KOUTRAKOS (ed.), European Foreign Policy: Legal and Political perspectives, Edward Elgar, 2011; Christophe HILLION, "Cohérence et action extérieure de l'Union Européenne», EUI Working Papers, LAW 2012/14. Sobre la coordinación 
ello pesa también en relación con los asuntos árticos. Pero, además, en el escenario de la gobernanza ártica, en el que los Estados árticos reivindican su posición preeminente, las organizaciones internacionales son principalmente foros y no tanto actores. En cambio la UE no es un foro (como el Consejo Ártico, como la OMI ...) sino un actor (como lo son los Estados, árticos y no árticos), y por ello resulta singular. Una singularidad que debilita su posición.

Tal y como hemos visto anteriormente, el Ártico es susceptible de una triple aproximación: universal, regional y subregional. Y de algún modo parece que donde encuentra más resistencia la $\mathrm{UE}$ es en el nivel regional. La UE no cuenta con la complicidad de las potencias árticas en su intento de afirmarse como un actor ártico relevante, y ello va más allá de lo que pueda haber sido un problema puntual de sensibilidad ártica (la regulación relativa a la comercialización de los productos derivados de las focas $)^{74}$. Su «afecto no correspondido» con el Consejo Ártico, al que la UE reconoce expresamente como principal foro regional de cooperación ártica ${ }^{75}$, pero que no le otorga el

entre la UE y los Estados miembros en acción exterior, Mireia ESTRADA CAÑAMARES, «Coordinación vertical en la acción exterior de la UE: La dimensión jurídica», Revista Electrónica de Estudios Internacionales, núm.26, 2013. Sobre la cláusula de no afectación mutua entre la PESC y los restantes ámbitos de acción de la UE, Carmen MARTÍNEZ CAPDEVILA e Irene BLÁZQUEZ NAVARRO, «La incidencia del artículo 40 TUE en la acción exterior de la UE», Revista jurídica Universidad Autónoma de Madrid, núm.28, 2013, pp. 197-219. Otra cuestión son los acuerdos no vinculantes; en relación con la distribución de poderes entre las instituciones de la UE en relación con la adopción de tales instrumentos, Paula GARCIA ANDRADE, "The Distribution of Powers Between EU Institutions for Conducting External Affairs through Non-Binding Instruments», European Papers, vol. 1, núm.1, 2016, pp. 115-125. Thomas VERELLEN, "On Conferral, Institutional Balance and Non-binding International Agreements: The Swiss MoU Case», European Papers, vol. 1, núm.3, 2016, pp. 1225-1233.

74 Stępień y Koivurova consideran que la negativa de las potencias árticas a reconocer a la UE como un actor ártico relevante está ligada a la incomodidad que les provoca la retórica de los valores de la Unión, su rechazo de la UE como actor en las relaciones internacionales, y la preocupación de que la Comisión Europea intente coordinar la actuación de sus Estados miembros en el Consejo Ártico. Adam STĘPIEŃ y Timo KOIVUROVA, "The Making of a Coherent Arctic Policy for the European Union: Anxieties, Contradictions and Possible Future Pathways», en Adam STECPIEŃ, Timo KOIVUROVA y Paula KANKAANPÄ̈̈, The Changing Arctic and the European Union, Brill, 2016, pp. 34-42.

75 «La UE continuará su participación activa en el Consejo Ártico (el principal foro para debatir sobre cooperación internacional en la región) mediante, por ejemplo, la 
reconocimiento oficial de observador a pesar de su importante participación de facto, es un buen exponente ${ }^{76}$.

El nivel subregional nos lleva a distinguir entre el Oeste (nordeste de $\mathrm{Ru}-$ sia, Alaska, territorios septentrionales de Canadá, Groenlandia ${ }^{77}$; y aguas correspondientes) y el Este (Groenlandia, Islandia, territorios septentrionales de Noruega, Suecia y Finlandia, noroeste de Rusia; y aguas correspondientes) ${ }^{78}$. Y también un tercer ámbito geográfico que sería el océano Central Ártico; aunque susceptible de coincidencia parcial con los otros dos ámbitos sub-regionales si éstos son entendidos de un modo amplio (por ejemplo, el ámbito geográfico de la OROP de las aguas del atlántico nordeste — la CPANEalcanza aguas del océano Central Ártico).

Por lo que se refiere a la UE, su implicación en el Ártico occidental deriva de su participación en los foros universales; pensemos, por ejemplo, en el Código Polar para la navegación en todas las aguas polares, y por tanto también en las del Ártico occidental. Por el contrario, su implicación en el Ártico central es actualmente destacada. Se da la circunstancia de que prácticamente los mismos Estados que no reconocen a la UE como observadora del Consejo Ártico (nos referimos a los A8), aceptan su participación como miembro del proceso negociador relativo a la pesca en aguas en el océano Central Ártico (nos referimos a los A5). Sin embargo, imaginamos que esto se debe principalmente a dos motivos: la fuerza de los hechos porque la realidad es que la UE es la única representante de los intereses pesqueros de la Unión en las OROPs; y la ausencia de obstáculos formales que impidan de manera real —o que sirvan de excusa para ello - la participación de la UE (pensemos en el citado ejemplo de la OMA, ámbito también exclusivo de la UE, pero en el que se requiere

participación y la contribución a la labor de los grupos de trabajo o de expertos pertinentes» (Comunicación de la Comisión de 2016, cit., nota 7, punto 3.1).

Dado que la UE ya es observadora $a d$ hoc, se suele destacar el importante valor simbólico del reconocimiento. Así, Elena CONDE PÉREZ, Zhaklin Valerieva YANEVA, "The European Arctic policy in progress», Polar Science, núm.10, 2016, pp. 441-449, p. 441.

77 La parte occidental de Groenlandia, orientada geográficamente hacia Canadá, está vinculada al Ártico occidental, y ello es especialmente claro en materia de navegación y pesca. En cuanto a la parte oriental de Groenlandia, orientada geográficamente hacia Islandia y Noruega, sería fácil situarla en el Ártico oriental. A ello se añade su pertenencia a un Estado europeo (Dinamarca). Por esta razón, a los efectos del presente estudio, la incluimos en ambas subregiones.

78 Tomamos los términos «Este» $\mathrm{y}$ «Oeste» a los solos efectos del presente trabajo, e inspirados por la terminología de las rutas marítimas (paso del nordeste y paso del noroeste). 
la enmienda del convenio para admitir su incorporación como miembro). En tercer lugar, el Ártico oriental nos remite a lo que comúnmente es identificado como Ártico europeo y que, lógicamente, es donde la UE encuentra mayor acomodo, puesto que pertenece geográficamente a ella.

El Ártico europeo conforma un amplio espacio bajo la soberanía y jurisdicción estatal: Estados miembros de la UE (Suecia, Finlandia, Dinamarca*79) y terceros Estados (Islandia, Noruega, Rusia, Groenlandia*). Pero también comprende espacios no sujetos a soberanía y jurisdicción estatal (alta mar y Zona Internacional de Fondos Marinos). Su construcción como espacio con identidad propia es un proceso todavía en marcha en el que la UE está llamada a jugar un importante papel. Por otro lado, la controversia acerca de la aplicación del derecho de la UE vía acuerdo EEE en las aguas islandesas y noruegas, es una cuestión pendiente que condiciona el alcance del derecho de la UE en relación con el Ârtico.

\section{EL ÁRTICO EUROPEO}

El Ártico es un espacio de geometría variable dependiendo del asunto que tratar (fauna, flora, desarrollo humano, navegación, etc.), pero los criterios más utilizados son la temperatura (valores máximos bajos) y la latitud (círculo polar ártico $)^{80}$. Con carácter general el criterio de temperatura conduce a una delimitación más amplia tanto en relación con el Ártico occidental (fundamentalmente por la inclusión del mar de Bering) como oriental (fundamentalmente por la inclusión de Islandia ${ }^{81}$ ), pero en ningún caso incluye las aguas marinas suecas o finlandesas. La referencia a las «aguas árticas de la UE», utilizada por el PE en su resolución de 2017, resulta confusa ${ }^{82}$. Cuestión

79 Recordamos que Dinamarca es Estado miembro de la UE, y Groenlandia forma parte de Dinamarca pero no es territorio de la UE. Por esta razón hemos marcado Dinamarca y Groenlandia con un asterisco.

80 El criterio de la temperatura toma como límite los valores medios máximos, entendiendo que serán árticos aquellos territorios en los que la temperatura media durante el mes de julio no supera los $10^{\circ} \mathrm{C}$. El criterio de latitud toma como referencia el círculo polar ártico $\left(66^{\circ} 33^{\prime} \mathrm{N}\right)$.

81 Si tomamos como criterio la latitud, Islandia solo cuenta con un territorio en el Ártico: la Isla de Grimsey; el resto de Islandia se sitúa al sur del círculo ártico. Si tomamos como criterio la temperatura, toda Islandia puede ser considerada ártica.

82 Resolución del PE de 2017, cit., nota 8, punto 14: «[...] pide que se prohíba la perforación en busca de petróleo en las aguas árticas heladas de la Unión y del EEE [...]». Raspotnik y Stępień se preguntan a qué aguas de la UE alude el PE en su resolución y señalan que aunque las aguas del Golfo de Botnia son «aguas heladas de la UE», sin 
diferente es la aplicación del derecho de la Unión en aguas marinas árticas, ya sea por una aplicación extraterritorial o, como veremos en el epígrafe siguiente, su discutida aplicación en el marco del EEE.

Por otro lado, y puesto que vamos a referirnos al Ártico oriental como Ártico europeo es importante recordar que Europa no es sinónimo de Unión Europea. No lo es con carácter general, pero mucho menos cuando aludimos a la Europa ártica, que incluye más Estados fuera de la Unión (*Groenlandia, Islandia, Noruega, Rusia occidental) que dentro (Suecia, Finlandia, ${ }^{*}$ Dinamarca). Sin embargo, la inevitable asociación entre ambas (Europa y UE) ${ }^{83}$ puede resultar delicada. Tanto en relación con sus Estados árticos, celosos de su condición de miembros del Consejo Ártico ${ }^{84}$; muy especialmente Dinamarca ${ }^{85}$, dada su particular situación en relación con Groenlandia ${ }^{86}$. Como por parte de los Estados árticos no miembros de la Unión, fundamentalmente en relación con las aguas marinas.

embargo no se han descubierto depósitos de hidrocarburos. Andreas RASPOTNIK y Adam STĘPIEŃ, «The European Parliament heading towards icy Arctic waters again", The Arctic Institute, de 18 de abril de 2017, pp. 1-9, p. 3.

El llamado «rapto de Europa por la Unión Europea» al que simbólicamente alude Remiro Brotons para referirse a la progresiva identificación entre Europa y UE. Antonio REMIRO BROTONS, «Reflexiones sobre los límites de Europa como proyecto político", Curso de Derecho Internacional de Vitoria-Gasteiz, 2008, pp. 447-475, véase p. 450.

Raspotnik y Stępień destacan la llamada de atención a los Estados árticos de la UE que realiza el PE en su última resolución. RASPOTNIK y STĘPIEŃ, "The European...», op. cit., nota 82, p. 5. Resolución del PE de 2017, cit., nota 8, punto 22: « [...] pide a los Estados miembros que son miembros del Consejo Ártico que mantengan informados a los demás Estados miembros y al Alto Representante de la Unión [...] de cualesquiera cuestiones de interés común en el Consejo Ártico, de conformidad con el art. 34, apdo. 2, del Tratado de la Unión Europea».

85 Recientemente, con ocasión de su participación en un foro ártico internacional, Dinamarca insistió en el protagonismo de los Estados árticos, sin aludir a la UE. Subraya el protagonismo de los A5 y del Consejo Ártico, mientras su alusión a terceros es un llamamiento a la inversión en el que entremezcla agentes públicos y privados ( Developing the Arctic is not a task limited to the Arctic States. The world - both in terms of states, companies and organisations - is invited to join in on opportunities and partnerships»). Se alude al derecho internacional como marco de referencia, y más concretamente a la Convención de las Naciones Unidas sobre el Derecho del Mar (CNUDM). No hay mención a la UE (4 $4^{\text {th }}$ International Arctic Forum, Arkhangelsk, Rusia, 29-30 de marzo de 2017. Nota de prensa del Ministerio danés de Asuntos Exteriores; puede consultarse (texto en inglés) en The Arctic Journal, 30 de marzo, 2017, «Possibilities and challenges in the Arctic. Perspectives from the Kingdom of Denmark».

86 Groelandia no es parte de la UE, pero Dinamarca vela por los intereses de Groenlandia cuando desempeña su papel de miembro de la Unión. Por ejemplo, en relación 
La delimitación septentrional de las aguas marinas árticas europeas entra en colisión con la delimitación del océano Central Ártico; no tanto en un sentido geográfico, sino de gestión. Hasta ahora la inactividad en el océano Central Ártico inclinó la balanza hacia el Atlántico, pero esto está cambiando. Debemos recordar que las aguas marinas árticas no solo pertenecen al océano Ártico sino también al océano Atlántico (y si seguimos una delimitación amplia de la región ártica, también al océano Pacífico, pero ahora nos limitaremos al Atlántico). Lo que sucede es que tradicionalmente las aguas septentrionales del océano Atlántico han tenido una actividad pesquera y de navegación más parecida a la de las restantes aguas atlánticas que a la de las restantes aguas árticas, donde el hielo y las condiciones climáticas dificultaban o impedían tales actividades. Por esa razón, no ha sido hasta fechas recientes cuando se ha empezado a destacar el carácter ártico de las aguas atlánticas septentrionales. Por otro lado, y también debido a esa escasísima o nula actividad en las aguas del océano Central Ártico, algunas organizaciones han «atraído» hacia el Atlántico ciertas aguas del océano Central Ártico; así lo hace OSPAR ${ }^{87}$ en materia de gestión medioambiental marina, y así lo hacen la $\mathrm{FAO}^{88}$ y $\mathrm{CPANE}^{89}$ en relación con la pesca. De modo que, de acuerdo con esa delimitación amplia, podrían considerarse aguas marinas del

con la adopción de la regulación de productos derivados de las focas: «Statement by Denmark. Denmark has during the negotiations underlined the economic and cultural importance of seal hunting for Greenland [...] Denmark acknowledges that the Regulation permits trade in seal products resulting from hunts conducted by Inuit communities [...]» (Consejo de la Unión, Interinstitutional File:2008/0160 (COD), Bruselas, 20 de julio de 2009).

87 Art. 1 del Convenio OSPAR: «A los efectos del presente Convenio se entenderá por: a) "Zona marítima», las aguas [...] situados en los límites siguientes: i) las zonas de los Océanos Atlántico y Ártico y de sus mares secundarios, que se extienden al Norte del paralelo $36^{\circ}$ de latitud Norte y entre el meridiano $42^{\circ}$ de longitud Oeste y el $51^{\circ}$ de longitud Este, salvo: [...] ii) la zona del Océano Atlántico situada al Norte del paralelo $59^{\circ}$ de latitud Norte y entre el meridiano $44^{\circ}$ de longitud Oeste y el $42^{\circ}$ de longitud Oeste». DO L 104, de 3 de abril de 1998, pp. 2-21.

88 A efectos estadísticos pesqueros la FAO distingue diecinueve grandes zonas pesqueras. Las aguas árticas, entendidas en un sentido amplio que siga el criterio de la temperatura, aparecen distribuidas en cuatro zonas: zona 18 (mar Ártico), zona 21 (Atlántico noroccidental), zona 27 (Atlántico nordeste), y zona 67 (Pacífico nordeste). En la zona el Atlántico nordeste incluye también ciertas aguas del océano Central Ártico (las incluidas entre los meridianos 4000' Oeste y 68³0' Este).

89 La CPANE también incluye en su ámbito de actuación las aguas europeas del océano Central Ártico situadas entre el meridiano $42^{\circ}$ Oeste y el $51^{\circ}$ Este (y por encima de la latitud $59^{\circ}$ Norte, también las aguas entre el meridiano $42^{\circ}$ y el $4^{\circ}$ Oeste). 
Ártico europeo las incluidas en un triángulo que tenga por vértice el Polo Norte y limiten al Oeste y Este en torno a los meridianos $40^{\circ}-45^{\circ}$ Oeste y $50^{\circ}-70^{\circ}$ Este, respectivamente. Sin embargo, en materia de protección medioambiental marina, los Estados ribereños árticos europeos se resisten a la escala subregional europea (OSPAR), en favor de la escala regional (Consejo Ártico), como se puso de manifiesto en los trabajos para sacar adelante un Área Marina Protegida (AMP) en aguas de alta mar ártica ${ }^{90}$. Y en materia pesquera, está por ver cuál será el resultado del actual proceso negociador del océano Central Ártico (A5 + UE, Islandia, Japón, Corea, China). Por su parte, Islandia, rechazada por el grupo de Estados ribereños del océano Central Ártico a pesar de su enérgica protesta $^{91}$, afirma su peso no solo como miembro del Consejo Ártico sino también como aliado de China ${ }^{92}$, y con una clara visión de cuál debería ser su papel en una futura ruta transpolar ${ }^{93}$.

90 Esta propuesta fue debatida y rechazada por la Comisión OSPAR con ocasión de su reunión de junio de 2016 (Summary Record, OSPAR 2016, OSPAR 16/20/1-E, cit. nota 48). En esta reunión los Estados ribereños árticos miembros de OSPAR (Islandia, Dinamarca y Noruega) reivindicaron el papel de los Estados ribereños en relación con el océano Central Ártico destacando que tres de ellos (Estados Unidos, Canadá y Rusia) no eran miembros de OSPAR. Con ese argumento, alegaron que OSPAR no era el foro para discutir asuntos árticos en general, o un AMP ártica en particular, a diferencia del Consejo Ártico, que sí reúne a todos los Estados ribereños árticos. La posición de estos tres Estados fue rebatida por la UE y cuatro de sus Estados miembros (Francia, Alemania, Holanda y España), que recordaron el mandato de OSPAR para la designación de las AMP, y aunque destacaron el papel del Consejo Ártico, rechazaron que pueda erigirse como principal foro para la discusión de los asuntos árticos.

91 Puede consultarse la resolución aprobada el 28 de marzo de 2011 por el Parlamento islandés (Althingi) sobre la política ártica de Islandia; el texto en inglés («A Parliamentary Resolution on Iceland's Arctic Policy») está publicado en la web oficial del Ministerio de Asuntos exteriores de Islandia (https://www.mfa.is). En dicha resolución se alega que la condición de Islandia como Estado ribereño ártico tienen un fundamento jurídico, económico y geográfico, y se insiste especialmente en el hecho de que la zona septentrional de la zona económica exclusiva islandesa se sitúa en el Ártico.

92 Punto 61 de la Resolución del PE de 2017, cit., nota 8: "Subraya el interés cada vez mayor de China por la región ártica, especialmente en lo que respecta al acceso a las rutas marítimas y la disponibilidad de los recursos energéticos; toma nota de la celebración de un acuerdo de libre comercio entre Islandia y China, y pide a la Comisión que siga de cerca las repercusiones que dicho acuerdo pueda tener no solo en el desarrollo económico sostenible de la parte islandesa de la región ártica, sino también en la economía y en el mercado interior de la Unión;».

93 Existen numerosos estudios acerca de la progresiva navegabilidad de las aguas árticas (temporadas más amplias y trayectos realizables en menor número de días por lo que 
En todo caso, la construcción de un Ártico europeo no se apoya únicamente en una voluntad política, sino en una configuración geográfica, una tradición de vecindad en el continente europeo e, incluso, unas condiciones climáticas particulares ${ }^{94}$. Además, el progresivo calentamiento del Ártico, acorta en cierto modo las distancias con sus territorios más meridionales; como está sucediendo en el ámbito pesquero con el movimiento de pesquerías ${ }^{95}$, o puede suceder en el futuro en el ámbito de navegación con las rutas transpolares ${ }^{96}$.

El papel de la UE en la afirmación de un Ártico europeo va más allá de lo que pueda ser la política regional en sus territorios más septentrionales. La preeminencia de la dimensión marítima y exterior en la política ártica de la UE no tiene que conectar la acción exterior de la UE en asuntos árticos únicamente con una perspectiva global ${ }^{17}$. Europa no es la Unión Europea,

se refiere a los pasos del noroeste y, sobre todo, del nordeste; futura posibilidad de navegación en la ruta transpolar). Entre otros, el publicado en septiembre de 2016: Nathanael MELIA, Keith HAINES, Ed HAWKINS, "Sea ice decline and 21st century trans-Arctic shipping routes», Geophysical Research Letters, vol. 43, 2016, pp. 9720-9728.

94 En palabras del ministro de Asuntos Exteriores de Noruega: «We are not talking about a homogenous region. There is not one Arctic. There are many Arctics. Because of the North Atlantic Current, temperature and ice conditions in the -mostly ice-freeNorwegian part of the Arctic are vastly different from those of Alaska. Climatic conditions and the amount of human activity vary greatly across the region»; BRENDE, op. cit., nota 67.

95 El calentamiento de las aguas marinas puede provocar que ciertas pesquerías se muevan hacia aguas septentrionales más frías, como ya ha sucedido con la caballa y el arenque atlántico-escandinavo, generando en 2013-2014 una controversia comercial entre la Unión y las Islas Feroe, ya resuelta. Rosa María FERNÁNDEZ EGEA, «Cambio climático y la sostenibilidad de los recursos pesqueros del mar del norte. La controversia comercial entre la Unión Europea y las Islas Feroe», Revista del Instituto Español de Estudios Estratégicos, núm. 4, 2014, pp. 1-22.

96 En el ámbito de la navegación, el progresivo deshielo abrirá la posibilidad de rutas transpolares (atravesando el océano Central Ártico) que, además de aportar ventajas económicas (tiempo, combustible), disminuye la dependencia respecto de los Estados que son ribereños de las actuales rutas del noroeste (Canadá) y del este (Rusia).

97 Por el contrario, en su Dictamen de 2017 (cit., nota 11), el Comité de las Regiones afirmaba en su punto 8: «[el Comité de las Regiones] señala que la Comunicación [de la Comisión y la alta representante] considera la región del Ártico desde dos puntos de vista diferentes. Visto desde la perspectiva de Europa, las regiones más septentrionales de Europa se encuentran en la región ártica y se caracterizan por su lejanía, condiciones difíciles, una escasa densidad de población y el envejecimiento de esta. Desde una 
y mucho menos en un futuro próximo en el que la retirada de Reino Unido previsiblemente reducirá el peso de la Unión ${ }^{98}$.

\section{EL ESPACIO ECONÓMICO EUROPEO 99}

Quizá al abordar el tema de las fronteras de la Unión, el primer pensamiento se dirige a las fronteras meridional y oriental de la Unión porque son las que plantean mayores tensiones; fundamentalmente el desafío migratorio y la compleja relación con Rusia. Pero también porque nuestros vecinos noroccidentales — Noruega e Islandia— tienen en cierto modo un pie dentro ${ }^{100}$.

perspectiva global ártica, la Comunicación destaca los recursos naturales (minerales, bosques, economía marítima y pesca), comunidades altamente desarrolladas y sólidos conocimientos técnicos, por ejemplo, a la hora de desarrollar soluciones tecnológicas sostenibles desde el punto de vista medioambiental».

Stępień y Raspotnik consideran que es poco probable que las prioridades de la Unión en el Ártico cambien como resultado de la retirada del Reino Unido, pero sí creen que tendrá consecuencias; fundamentalmente por tres razones: a) por la energía que el proceso del brexit requerirá de las instituciones europeas, y que restará atención a asuntos — que ellos califican de marginales - como el Ártico; b) por el protagonismo británico en materia ártica (investigación polar, actividades económicas en la zona, y el sector de seguros marítimos), que ya no será un activo para el perfil ártico de la Unión; y c) por la reducción presupuestaria que sufrirá la UE al dejar de contar con la aportación británica, aunque los recortes pueden ser menores en materia de investigación si Reino Unido, aun fuera de la Unión, participa en el programa que suceda al programa Horizonte 2020. Adam STEPIEŃ y Andreas RASPOTNIK, «The EU's Arctic Future Following the Spring of Statements», Arctic Yearbook 2016, 2016, pp. 396-400, p. 399.

99 El Acuerdo del Espacio Económico Europeo (EEE) se firmó en 1992 y entró en vigor en 1994. Es un acuerdo entre, por una parte la UE y sus Estados miembros, y por otra parte los Estados miembros de la Asociación Europea de Libre Comercio (AELC), menos Suiza. Texto en DO L 1, de 3 de enero de 1994, pp. 3-522. Actualmente conforman el EEE un total de 31 Estados: los veintiocho miembros de la UE, y tres miembros de la AELC (Noruega, Islandia, Liechtenstein).

${ }^{100}$ En 2010 el Gobierno noruego encargó a un grupo de expertos independientes la elaboración de un informe en profundidad sobre los acuerdos de Noruega con la UE. El informe, un extenso documento de novecientas páginas presentado el 17 de febrero de 2012, aludía en su título a esta misma idea de estar, al mismo tiempo, «dentro y fuera» de la UE. El informe está en noruego pero se publicó un resumen de dieciocho páginas en inglés: Outside and Inside. Norway's agreements with the European Union, Official Norwegian Reports NOU 2012: 2, chapter 1 . 
En la distinción de fronteras interiores y exteriores de la Unión ${ }^{101}$, la participación de Noruega e Islandia desde hace más de veinte años en el mercado interior (EEE, 1994- ) $)^{102}$ y en el Espacio Schengen (1996- ) ${ }^{103}$, completada además con la cooperación en otros ámbitos, ha ido conformando una nueva categoría — de frontera, de vecindad...— ${ }^{104}$ que es de particular interés cuando abordamos la política ártica. Muy especialmente por lo que se refiere a Noruega, que comparte frontera terrestre con Suecia y Finlandia; por ejemplo, regiones árticas y subárticas de estos tres países con una serie de importantes desafíos en común han constituido una red - NSPA — con la que dan a conocer su situación y tratan de influir en la política de la $\mathrm{UE}^{105}$.

Noruega e Islandia no son miembros de la Unión, y al formar parte del EEE no han cedido el ejercicio de competencias soberanas a una organización

101 Fronteras interiores entre los Estados miembros de la UE y fronteras exteriores con terceros Estados. Tomamos la expresión enunciada por Del Valle: «Modelo europeo de fronteras». José Alejandro DEL VALLE GÁLVEZ, «Las fronteras de la Unión: el modelo europeo de fronteras», Revista de Derecho Comunitario Europeo, núm.12, 2002, pp. 299-341.

102 Liechtenstein también es miembro del EEE pero no es relevante a los efectos de este trabajo, centrado en el Ártico.

103 La participación se inició en 1996 (Acuerdo de Luxemburgo de 19 de diciembre de 1996 entre los entonces trece Estados miembros de la UE signatarios de los acuerdos de Schengen e Islandia y Noruega). La posterior integración del acervo Schengen en la UE —integración con ocasión del Tratado de Ámsterdam - lleva a concluir en 1999 un nuevo acuerdo (Acuerdo con Islandia y Noruega sobre la asociación de estos dos Estados a la ejecución, aplicación y desarrollo del acervo de Schengen; DO L 176, de 10 de julio de 1999 , pp. 35 y ss.).

104 Algunos autores hablan incluso de «integración diferenciada». Morten EGEBERG y Jarle TRONDAL, "Differentiated Integration in Europe: The Case of EEA Country, Norway», Journal of Common Market Studies, vol. 37, núm. 1, 1999, pp. 133-142. Nicole STOFFEL VALLOTTON, «El Espacio Económico Europeo: un ejemplo de integración diferenciada en las relaciones exteriores de la Unión Europea. La aplicación del acervo comunitario a terceros Estados», Revista de Derecho Comunitario Europeo, núm.15, 2003, pp. 573-625.

105 En realidad no se identifican por su carácter ártico/subártico, sino geográfico y poblacional: Red de las Regiones Septentrionales de Escasa Densidad Demográfica, también conocida por sus siglas en inglés: NSPA (Northern Sparsely Populated Areas Network). Son un total de catorce regiones de Noruega (norte), Suecia (norte y centro), Finlandia (norte y este). Además de servir de plataforma de buenas prácticas, esta red trabaja para influir en la política de la UE. Como es lógico, han seguido muy de cerca la evolución de la política ártica de la UE adoptando, en los diferentes momentos, su posición al respecto. 
internacional; se da la circunstancia, incluso, de que ambos son Estados de tradición jurídica dualista. Sin embargo, al ser parte del EEE estos dos Estados han limitado su autonomía en importantes ámbitos ${ }^{106}$. A pesar de que la posible participación en el debate previo a la adopción del derecho de la Unión con relevancia para el $\mathrm{EEE}^{107}$ parece ser satisfactoria ${ }^{108}$, al final la «decisión», entendida como contenido de la norma en cuestión, es tomada únicamente por la UE. Los Estados EEE-AELC ${ }^{109}$ no forman parte de las instituciones de la UE, y por tanto tampoco de sus instituciones normativas (PE, Consejo, Comisión). En los ámbitos materiales del EEE, el derecho de la Unión no es directamente aplicable en Noruega e Islandia pero, una vez efectuada la incorporación al Acuerdo $\mathrm{EEE}^{110}$, en su caso con las modificaciones que pue-

106 Hans Petter GRAVER, "Supranationality and National Legal Autonomy in the EEA-agreement», ARENA (Centre for European Studies, University of Oslo), Working Papers, WP 00/23, 2000.

107 En relación con los actos de la UE referidos a sectores regulados por el Acuerdo EEE, los Estados AELC-EEE (acerca del uso de esta expresión, véase infra nota 109) podrán participar en la fase previa a su adopción (arts. 99 y 100 del Acuerdo EEE). Así, además de la consulta a los expertos de dichos Estados por parte de la Comisión Europea cuando esta ejerza la iniciativa para la adopción de actos legislativos, se prevé la posible participación del Comité Mixto del EEE (proceso de información y consulta a iniciativa de alguna de las partes contratantes del acuerdo) en la fase previa a la decisión del Consejo de la Unión. Y cuando la Comisión Europea adopte actos de ejecución, se prevé la participación de los Estados EEE-AELC en los comités consultivos. Por otro lado, en el Acuerdo EEE también se contempla la cooperación no relacionada con las cuatro libertades (comités del art. 81 del Acuerdo EEE); y otros comités referidos a áreas muy específicas (art. 101 y Protocolo 37 del Acuerdo EEE). Finalmente, a todo esto hay que añadir que, además de lo previsto en el Acuerdo, se ha ido consolidando una práctica de participación en relación con el Consejo; tanto en grupos de trabajo del Consejo (participación de funcionarios) como en reuniones informales y conferencias ministeriales (participación de ministros). Puntos 26 y 27 de las conclusiones del $46^{\circ}$ Consejo EEE, celebrado el 15 de noviembre de 2016.

108 Punto 28, ibid.

109 Los Estados EEE-AELC son los Estados del AELC que forman parte del EEE, esto es: Noruega, Islandia, Liechtenstein.

110 El Comité mixto del EEE — integrado por representantes de la UE y de cada uno de los tres Estados (Noruega, Islandia, Liechtenstein) — será quien decida qué actos de la Unión se incorporan al Acuerdo EEE. La incorporación se efectúa mediante la inclusión de dichos actos en la lista de protocolos y anexos al Acuerdo EEE; a partir de ahí, cada Estado adoptará el acto nacional que, en su caso, pueda ser necesario (Noruega e Islandia son dualistas; Liechenstein no). Puede consultarse el documento «How EU acts become EEA acts and the need for adaptations» elaborado por el Comité Perma- 
dan ser necesarias ${ }^{111}$, será de obligado cumplimiento mediante la adopción de la correspondiente normativa nacional. Para aludir a este proyecto en el que confluyen dos procesos (UE y EEE) que no llegan a confundirse pero en el que uno (UE) marca el paso al otro (EEE) se habla de «homogeneidad dinámica» ${ }^{112}$.

Sin entrar ahora a evaluar lo que es la incorporación del derecho de la Unión al Acuerdo EEE en general ${ }^{113}$, sí resulta de especial interés para el presente trabajo la controvertida delimitación del ámbito espacial del Acuerdo EEE; controvertida por lo que se refiere a las aguas marinas de los Estados EEE-AELC. La interpretación que Noruega realiza del término «territorio» a efectos del Acuerdo EEE es un obstáculo para la aplicación del derecho de la UE vía Acuerdo EEE en las aguas marinas árticas noruegas e islandesas.

La determinación del ámbito de aplicación territorial del Acuerdo EEE ${ }^{114}$ es una cuestión a la que no se le prestó mucha atención en las negociaciones ${ }^{115}$ y que finalmente se concretó en una fórmula clásica que alude al territorio de los Estados, tanto al de los Estados de la UE como al de Noruega, Islandia y

nente de los Estados AELC (Standing Committee of the EFTA States, Subcommittee V: On Legal and Institutional Questions), ref. 1113623, de 23 de mayo de 2013.

111 La posición de la UE en relación con las disposiciones del Comité Mixto del EEE será aprobada por la Comisión o el Consejo, según los casos. Por la Comisión en relación con las disposiciones del Comité Mixto del EEE cuyo objeto sea una simple extensión de actos de derecho de la Unión al EEE, en su caso mediante adaptaciones técnicas. Y por el Consejo - a propuesta de la Comisión — cuando las modificaciones superen las adaptaciones técnicas. Art. 1, apdos. 2 y 3, del Reglamento (CE) núm. 2894/94 del Consejo relativo a determinadas normas de desarrollo del Acuerdo sobre el EEE (DO L 305, de 30 de noviembre de 1994, pp. 6-8).

${ }^{112}$ Hans Petter GRAVER, "Possibilities and Challenges of the EEA as an Option for the UK After Brexit», European Papers, vol. 1, núm. 3, 2016, pp. 803-821, véase pp. 806808.

113 El impacto es enorme. En 2012, aproximadamente tres cuartas partes de todos los actos legislativos de la UE habían sido incorporados a la legislación noruega (informe Outside and Inside, cit. nota 99, p. 6). Aunque el ritmo no es satisfactorio y el número de actos de la UE a la espera de ser incorporados es muy alto, tal y como ha sido reconocido recientemente por el Consejo EEE (punto 16 de la conclusiones del $46^{\circ}$ Consejo EEE, cit. nota 107).

114 Sobre esta cuestión puede consultarse Knut ALMESTAD, «The Notion of Opting out» (pp. 85-94) y «Natural Resources» (pp. 763-772), ambos capítulos en Carl BAUDENBACHER (ed.), The Handbook of EEA Law, Springer, 2016; véase pp. 90-91 y 768-770.

115 Ibid., p. 768. 
Liechtenstein ${ }^{116}$. Sin embargo, el alcance del término "territorio» en relación con los espacios marinos de los Estados EEE-AELC (Noruega e Islandia, pues Liechtenstein es un Estado sin litoral) presenta problemas.

Aunque ciertos actos de derecho de la Unión con incidencia en la zona económica exclusiva y en la plataforma continental sí han sido incorporados al Acuerdo EEE y, consecuentemente, al derecho noruego ${ }^{117}$, Noruega sostiene que a efectos de la aplicación del Acuerdo EEE el término «territorio» incluye, además del espacio terrestre, las aguas interiores y el mar territorial, pero no la zona económica exclusiva ni la plataforma continental ${ }^{118}$. La discrepancia se ha ido manteniendo pacíficamente, hasta la adopción de dos directivas que Noruega se niega a aplicar ${ }^{119}$ : la directiva marco sobre la estrategia marina de

116 Art. 126 del Acuerdo EEE.

117 Así es señalado por Das Neves, que se hace eco de esta polémica. Maria Madalena DAS NEVES, The Legal Framework for Norway's External Energy Trade and Investment Relationships, véase pp. 154-157, tesis doctoral defendida el 24 de febrero de 2017 en la Facultad de Derecho de la Universidad de Tromsø, Noruega (UiT Arctic University of Norway); agradecemos a M. M. Das Neves que nos haya facilitado un ejemplar de su tesis. La autora cita como ejemplos las directivas de licencias de hidrocarburos (Directiva 94/22/CE) y del mercado interior del gas (Directiva 2003/55/CE). La Directiva 94/22/CE sobre las condiciones para la concesión y el ejercicio de las autorizaciones de prospección, exploración y producción de hidrocarburos fue incorporada al Acuerdo EEE mediante Decisión del Comité Mixto del EEE núm.19/95; DO L 158, de 8 de julio de 1995, pp. 40-41. La Directiva 2003/55/CE sobre normas comunes para el mercado interior del gas natural fue incorporada al Acuerdo EEE mediante Decisión del Comité Mixto del EEE núm.46/2005; DO L 53, de 23 de febrero de 2006, pp. 43-45. Por nuestra parte, tan solo añadir que esta última Directiva 2003/55/CE ha sido derogada por la Directiva 2009/73/CE, también aprobada como «Texto pertinente a efectos del EEE» y que, sin embargo, no ha sido incorporada al Acuerdo EEE.

118 En octubre de 2012, y sobre la base de un informe de expertos (cit. nota 100), el Gobierno noruego presentó ante el Parlamento noruego un libro blanco relativo a los acuerdos de Noruega con la UE, en adelante, libro blanco noruego. Está disponible en inglés en la propia página web de la representación de Noruega ante la UE. Norwegian Ministry of Foreign Affairs, The EEA Agreement and Norway's other agreements with the EU, Meld. St. 5 (2012 - 2013) Report to the Storting (White Paper), p. 13.

119 Fredriksen y Franklin señalan que esta discrepancia se ha llevado tradicionalmente de manera pacífica («agree to disagree»). En ciertas ocasiones en que Noruega se ha visto presionada por el órgano de vigilancia de la AELC (los autores aluden al menos a dos asuntos, en 1999 y 2004), Noruega ha optado por cumplir, pero declarando que lo hacía voluntariamente y no porque aceptase la aplicación del Acuerdo EEE más allá de sus aguas territoriales. Los autores consideran que la posición noruega respecto a estas 
$2008^{120}$, y la Directiva sobre la seguridad de las operaciones relativas al petróleo $\mathrm{y}$ al gas mar adentro de $2013^{121}$. Aunque ambas fueron aprobadas como «texto pertinente a efectos del EEE», no han sido incorporadas al Acuerdo EEE ${ }^{122}$. Por lo que se refiere a la Directiva marco sobre la estrategia marina, fue en 2011 cuando Noruega declaró que no podía incorporarse al Acuerdo EEE ${ }^{123}$; su estrategia no fue limitar su aplicación a aguas interiores y mar territorial, sino simplemente descartar la aplicación de la Directiva ${ }^{124}$. Islandia sí se dispuso a transponerla pero fue en el marco de las negociaciones - posteriormente suspendidas - de adhesión a la UE ${ }^{125}$. Por su parte, la Directiva sobre seguridad de las operaciones relativas al petróleo y al gas mar adentro determina que, a los efectos de su aplicación, el término "mar adentro» incluye las aguas territoriales, la zona económica exclusiva, o la plataforma continental ${ }^{126}$. Noruega

dos directivas (véase infra notas 120 y 121) parece marcar un cambio. Halvard Haukeland FREDRIKSEN y Christian N.K. FRANKLIN, "Of pragmatism and principles: The EEA Agreement 20 years on", Common Market Law Review, núm.52, 2015, pp. 629-684; véase pp. 655-656.

120 Directiva 2008/56/CE del PE y del Consejo, de 17 de junio de 2008, por la que se establece un marco de acción comunitaria para la política del medio marino (directiva marco sobre la estrategia marina). DO L 164, de 25 de junio de 2008, pp. 19-40.

121 Directiva 2013/30/UE del PE y del Consejo, de 12 de junio de 2013, sobre la seguridad de las operaciones relativas al petróleo y al gas mar adentro, y que modifica la Directiva 2004/35/CE. DO L 178, de 28 de junio de 2013, pp. 66-106.

122 Así puede consultarse en la base EEA-Lex (http://www.efta.int/eea-lex). En relación con las citadas directivas véase ref. 32008L0056 (directiva sobre estrategia marítima) y ref. 32013L0030 (directiva sobre seguridad mar adentro).

123 Libro blanco, cit., nota 118, p. 14.

124 Johansen señala que, con carácter general, la aplicación del derecho de la Unión vía Acuerdo EEE ha influido de manera importante en el derecho medioambiental noruego; especialmente dotándolo de mayor precisión y, de esa manera, limitando el poder discrecional de la Administración noruega. Sin embargo, según afirma la autora, la firme y clara posición de Noruega acerca de la delimitación del ámbito de aplicación geográfico del Acuerdo EEE (en el sentido de afirmar que no alcanza la zona económica exclusiva y la plataforma continental) ha tenido como efecto que las aguas marinas noruegas hayan quedado al margen del desarrollo medioambiental marino del derecho de la Unión. La autora se refiere concretamente a la directiva marco sobre la estrategia marítima. Elise JOHANSEN, «The EU Influence on Norwegian Domestic Legislation for the Protection of the Arctic Marine Environment», International Journal of Marine and Coastal law, 2017, en prensa. Agradecemos a la autora que nos haya facilitado su trabajo.

125 Screening report Iceland, chapter 27, Environment, de 25 de octubre de 2011, p. 6.

126 Art. 2, Directiva 2013/30/UE, cit. nota 121. 
e Islandia rechazan que sea de aplicación en el EEE alegando que la Directiva excede el ámbito geográfico —y también el material, por no afectar al buen funcionamiento del mercado interior sino a la seguridad- del Acuerdo $\mathrm{EEE}^{127}$.

La posición mantenida por Noruega es la de ajustarse a la interpretación dominante de "territorio» en derecho internacional. Respecto a Islandia, no nos consta que haya adoptado ningún posicionamiento oficial ${ }^{128}$.

El Acuerdo EEE establece que el ámbito de aplicación en relación con Noruega (e Islandia y Liechtenstein) será su territorio ${ }^{129}$, reconociéndole como única posible excepción el archipiélago de Svalbard ${ }^{130}$. Pero Noruega alega que, a estos efectos, es de aplicación la definición de territorio que se maneja en derecho internacional ${ }^{131}$. Con este razonamiento, excluye del ámbito de aplicación del Acuerdo EEE los espacios marinos sujetos a competencias funcionales del Estado, pero que no forman parte propiamente de su territorio, esto es, la plataforma continental y las aguas de la zona económica exclusiva. Este posicionamiento respecto al Acuerdo EEE no es exactamente igual al mantenido a propósito del Tratado de Svalbard ${ }^{132}$ - lo cual incluso podría

127 Claudia CINELLI, «Legal Status and Environmental Protection of the Arctic Sea-ice: European Perspectives», en Elena CONDE y Sara IGLESIAS (ed.), Global Challenges in the Arctic Region Sovereignty Environment and Geopolitical Balance, Routledge, 2017, pp. 129-146, véase pp. 139-140.

128 El 22 de marzo de 2017 dirigimos una pregunta escrita sobre esta cuestión al Ministerio de Asuntos Exteriores de Islandia, a través de la página web que tienen habilitada para consultas (https://www.mfa.is/enq). Ese mismo día nos remitieron confirmación de recepción. En la fecha de cierre de este trabajo (18 de mayo de 2017) no habíamos recibido ninguna respuesta.

129 Art. 126.1 del Acuerdo EEE: «El presente Acuerdo se aplicará a [...] y a los territorios de [...] la República de Islandia, el Principado de Liechtenstein, el Reino de Noruega $[\ldots] »$.

130 Acuerdo sobre el EEE, Protocolo 40 sobre Svalbard, DO L 1, de 3 de enero de 1994, p. 208.

131 "The EEA Agreement applies to the territory of the Kingdom of Norway, but not to Svalbard. Norway's position is that the term territory is to be understood in accordance with established practice in international law. This means that the EEA Agreement applies to Norwegian land territory, internal waters and territorial waters, but not to the exclusive economic zone, the continental shelf or the high seas». Libro blanco, cit., nota 118, p. 13.

132 Sobre el ámbito de aplicación espacial del tratado de Svalbard, entre otros. Robert CHURCHILL y Geir ULFSTEIN, «The disputed maritime zones around Svalbard», en Myron H. NORDQUIST, John NORTON MOORE, y Tomas H. HEIDAR, Changes in the Arctic Environment and the Law of the Sea, Brill, 2010, pp. 551-593; 
ser una estrategia defensiva útil para blindar su posicionamiento respecto a Svalbard-, aunque llega al mismo resultado.

En virtud del Tratado de Svalbard ${ }^{133}$, concluido hace casi un siglo, se reconoce la soberanía noruega sobre las tierras y aguas territoriales del archipiélago de Svalbard, situado en el mar de Barents. La soberanía noruega está sujeta a una serie de condiciones recogidas en el propio Tratado, y que Noruega ha tratado de limitar afirmando que el tratado no se aplica más allá del mar territorial, por entender que el ámbito de aplicación actual es el mismo de entonces (1920), cuando las aguas colindantes con el mar territorial eran aguas de alta $\operatorname{mar}^{134}$. A los efectos del presente trabajo no es relevante el detalle de los problemas pesqueros que en los últimos años se han venido planteando entre Noruega y la UE en relación con estas aguas, pero sí el hecho de que con ocasión de los mismos la UE se ha mostrado contraria a la interpretación restrictiva que defiende Noruega. La Unión se ha manifestado no solo en relación con las aguas, sino también, más recientemente, respecto a la plataforma continental, por verse implicada una especie sedentaria —el cangrejo de las nieves - que habita sobre la misma ${ }^{135}$.

José Luis MESEGUER, «Régimen jurídico de los espacios marítimos de Spitzsberg (Svalbard). Posición de Noruega, España y otros Estados», Revista Española de Derecho internacional, núm. 59-2, 2007, pp. 631-663; Erik J. MOLENAAR, "Fisheries Regulation in the Maritime Zones of Svalbard", The International Journal of Marine and Coastal Law, 27, 2012, pp. 3-58; Marta SOBRIDO PRIETO, «The Position of the European Union on the Svalbard Waters», en CONDE e IGLESIAS, op. cit., nota 127 , pp. $75-106$.

133 Tratado firmado en París en 1920 (por eso también se conoce como Tratado de París) y en vigor desde 1925. La denominación oficial del Tratado utiliza el que entonces era el nombre del archipiélago («Treaty Concerning the Archipelago of Spitsbergen»), y que fue posteriormente modificado. Las versiones oficiales (en inglés y francés) del Tratado están disponibles en la base de datos jurídica noruega Lovdata: http://emeritus.lovdata.no/traktater/texte/tre-19200209-001.html.

${ }^{134}$ La no aplicación de Tratado de Svalbard en la zona económica exclusiva y en la plataforma continental tiene gran importancia a efectos pesqueros y de explotación de hidrocarburos porque el tratado reconoce, entre otras cosas, el principio de no discriminación para la explotación de recursos en favor de todos los nacionales de los Estados parte en el Tratado. Además, y esto es muy importante desde la perspectiva de los hidrocarburos, establece importantes limitaciones fiscales.

135 Véase el considerando 35 del Reglamento (UE) 2017/127 del Consejo por el que se establecen, para 2017, las posibilidades de pesca para determinadas poblaciones y grupos de poblaciones de peces, aplicables en aguas de la Unión y, en el caso de los buques pesqueros de la Unión, en determinadas aguas no pertenecientes a la Unión, DO L 24, de 28 de enero de 2017, pp. 1-172. 
Por su parte, la UE ha tenido que ocuparse de esta cuestión también en relación con sus propios Estados miembros. No porque estos se hayan negado, con carácter general, a aplicar el derecho de la Unión en su zona económica exclusiva o en su plataforma continental (basta pensar en la gestión de los recursos biológicos marinos de esos espacios en el marco de la Política Pesquera Común de la Unión); sino en la medida en que tales espacios se han identificado, a determinados efectos, como «territorio» del Estado. Teniendo que decidir si el trabajo realizado en un buque colocador de tuberías o en una instalación — situados tanto el buque como la instalación sobre la plataforma continental de un Estado- podía ser considerado como trabajo en el territorio de dicho Estado, el TJUE dio una respuesta negativa en relación con el buque (sentencia Kik) ${ }^{136}$ y, pese a la oposición del Estado afectado - Holanda-, dio una respuesta positiva en relación con la instalación (sentencias Weber y Salemink $)^{137}$. La base jurídica invocada por el TJUE ha sido la jurisdicción que la Convención de las Naciones Unidas sobre el Derecho del Mar (CNUDM) reconoce en sus arts. 79 y 80 al Estado ribereño sobre cables/ tuberías submarinos (no extensible a los buques que las colocan), y sobre islas artificiales/instalaciones/estructuras sobre la plataforma continental (los buques no se asimilan a esta categoría). Tampoco la entrega e instalación de un cable en la plataforma continental ha sido considerada por el TJUE, a efectos fiscales, como actividad desarrollada en el territorio del Estado; y nuevamente la justificación no es solo su localización geográfica extraterritorial, sino el hecho de que la actividad en cuestión no se encuentra entre las actividades recogidas en los arts. 56 y 77 CNUDM, relativos a los derechos y jurisdicción que puede ejercer el Estado ribereño sobre la zona económica exclusiva y la plataforma continental, respectivamente (sentencia $N N)^{138}$. En definitiva, el TJUE defiende una interpretación funcional de la noción de territorio que le

136 Sentencia del Tribunal de Justicia de 19 de marzo de 2015, Kik, C-266/13, EU:C:2015:188, apdos. 40-41.

137 Sentencias del Tribunal de Justicia de 27 de febrero de 2002, Weber, C-37/00, EU:C:2002:122, apdos. 27-36; de 17 de enero de 2012, Salemink, C-347/10, EU:C:2012:17, apdos. 28-36; sobre la oposición de Holanda, apdo. 30. Puede consultarse, entre otros. JAVIER A. GONZÁLEZ VEGA, «¿A vueltas con la «obsesión por el territorio»? El Tribunal de Justicia, la plataforma continental y la aplicación espacial del Derecho de la UE», Revista General de Derecho Europeo, núm. 30, 2013; Jorge A. QUINDIMIL LOPEZ, «La plataforma continental como ámbito de aplicación del derecho de la Unión Europea a la luz de la jurisprudencia del Tribunal de Justicia», Revista de Derecho Comunitario Europeo, núm. 48, 2014, pp. 529-549.

138 Sentencia del Tribunal de Justicia de 29 de marzo de 2007, Aktiebolaget NN, C-111/05, EU:C:2007:195, apdos. 51-61. 
lleva a considerar que zona económica exclusiva y plataforma continental son territorio de sus miembros - y por tanto territorio de la Unión- a efectos de las competencias que la CNUDM reconoce a los Estados ribereños en relación con estos dos espacios.

Teniendo en cuenta, entonces, que la UE no admite la tesis noruega en relación con el Tratado de Svalbard, y que además respecto al propio derecho de la Unión ha optado por una interpretación funcional, no parece probable que la UE vaya a admitir expresamente esa interpretación restrictiva en relación con el ámbito de aplicación territorial del Acuerdo EEE. Sin embargo, tampoco sabemos hasta qué punto querrá dar la batalla la UE en este momento; no nos consta que haya sometido esta cuestión al Comité Mixto del $\mathrm{EEE}^{139}$. Y además Noruega, con una actitud similar a la mantenida en materia pesquera en aguas de Svalbard, procura que la firmeza de su posicionamiento acerca del ámbito de aplicación espacial del Acuerdo EEE no impida, llegado el caso, el entendimiento acerca del contenido material de la regulación ${ }^{140}$. De modo que por el momento la controversia parece mantenerse con un perfil bajo, y aunque la reciente resolución del PE solicitando que la UE actúe en relación con las «aguas árticas de la UE y del EEE» ${ }^{141}$ no ha pasado desa-

139 Sobre la resolución de litigios relativos a la interpretación o aplicación del Acuerdo EEE, véase art. 111 del citado acuerdo. Asimismo, puede consultarse Christa TOBLER, «Dispute Resolution Under the EEA Agreement», en BAUDENBACHER, op. cit., nota 114, pp. 195-210.

140 "However, the geographical scope of the EEA Agreement is not considered to be a legal obstacle if Norway, after an assessment of a particular matter, decides to assume specific EEA obligations outside its territory»; Libro blanco, cit., nota 118, p. 13. Sobre el carácter problemático de aplicar voluntariamente, en la zona económica exclusiva y plataforma continental noruegas, normas del Acuerdo EEE sin admitir que dichos espacios forman parte del ámbito de aplicación espacial del Acuerdo EEE, véase ALMESTAD, op. cit., nota 114, p. 91.

141 Dejando a un lado la cuestión de las "aguas árticas de la UE» (ya comentado en el epígrafe anterior), por lo que se refiere a las «aguas árticas del EEE», se trata de las aguas de Islandia y Noruega (sin incluir las aguas noruegas de Svalbard, puesto que el archipiélago está expresamente excluido del ámbito de aplicación del Acuerdo EEE). Resolución del PE de 2017, cit. nota 8: punto 14: «[...] pide que se prohíba la perforación en busca de petróleo en las aguas árticas heladas de la Unión y del EEE [...]»; punto 60: «Recuerda que Islandia y Noruega se han comprometido en el marco del Acuerdo sobre el [...] EEE [...] a proteger la calidad del medio ambiente y velar por el uso sostenible de los recursos naturales, en consonancia con la legislación de la Unión al respecto». 
percibida, finalmente ha quedado más matizada de lo que se había previsto inicialmente ${ }^{142}$.

\section{CONSIDERACIONES FINALES}

La política ártica de la UE es una política relativamente joven que no arranca cuando la Unión pasa a tener territorio ártico ni cuando impulsa un plan de acción específico para esos territorios más septentrionales; su inicio es posterior a todo eso. El origen de esta política tiene lugar cuando, ya bien iniciado el presente siglo, la Unión, al igual que hicieron los propios Estados árticos por esas mismas fechas, identifica el Ártico como una región con entidad propia cuyas circunstancias requieren de una estrategia adecuada. Y en esta nueva política de la Unión, que todavía está en proceso de construcción, se percibe la creciente importancia del Ártico europeo, entendiendo europeo en su sentido genuino y, por tanto, no limitado a la UE. Frente a la asimilación de Ártico y océano Central Ártico, fomentada con bastante éxito por los Estados ribereños de dichas aguas, la aceptación e impulso del Ártico europeo como espacio con unas características específicas fortalece la posición de la Unión como actor ártico.

Los actos atribuibles a la Unión que tienen un impacto en la región ártica son adoptados en un doble plano. Por un lado, actos adoptados en un marco internacional multilateral, donde las competencias de la Unión son representadas, o bien directamente (por ejemplo, las actuales negociaciones relativas a la pesca en el océano Central Ártico, en las que la UE es una de las diez partes negociadoras), o bien a través de sus Estados miembros (por ejemplo, el Código Polar en materia de navegación, adoptado en la OMI, de la que no es parte la UE pero sí sus Estados miembros). Y por otro lado, actos adoptados en el seno de la Unión que no están dando cumplimiento a ningún compromiso internacional, y que tienen efectos: en el territorio ártico de la Unión (derecho de la Unión); en el territorio ártico de Noruega e Islandia (Acuerdo EEE); y/o en espacios árticos no sujetos a la soberanía o jurisdicción de ningún Es-

142 Destacan Raspotnik y Stępień que, en los borradores previos, la propuesta era prohibir la perforación en todas las aguas árticas bajo jurisdicción de la UE y del EEE, y no solo en las aguas heladas; fórmula que no fue bien recibida por Noruega. Señalan los autores que la referencia explícita a las aguas heladas es importante porque las aguas de las zonas económicas exclusivas de Islandia y Noruega (no incluida Svalbard) apenas están cubiertas de hielo. Y, además, la propia legislación noruega prohíbe ya la perforación en aguas heladas. RASPOTNIK y STĘPIEŃ, "The European...», op. cit., nota 82 , p. 3 
tado (aplicación extraterritorial del derecho de la Unión). Incluso actos cuya aplicación en territorio europeo de la Unión y/o el EEE tiene un impacto en territorios árticos no pertenecientes a la UE o al EEE (por ejemplo, el Reglamento sobre el comercio de productos derivados de la foca en el mercado de la Unión, cuya primera versión provocó el veto canadiense a la admisión de la UE como observadora permanente del Consejo Ártico).

Por lo que se refiere a los actos adoptados en un marco internacional multilateral, la estrategia internacional actual es sectorial y multinivel. Ciertamente, persisten campañas de sensibilización de la opinión pública mundial como la propuesta de un santuario ártico en el océano Central Ártico; tanto política como doctrinalmente avanza la reflexión sobre los derechos de la humanidad, y en el derecho internacional del mar se trabaja actualmente en el marco de Naciones Unidas sobre un posible tratado relativo a la diversidad biológica marina de las zonas situadas fuera de la jurisdicción nacional. Pero actualmente la protección internacional del Ártico no es omnicomprensiva, sino que se va articulando según ámbitos concretos (navegación, pesca, etc.), $y$ en foros de diferente alcance (universal, regional, subregional). En este escenario, la participación de la UE es desigual, ya que varía según el foro, y es asimétrica, porque no siempre se corresponde con las competencias que le han atribuido sus Estados miembros. No se trata de una situación exclusiva de la gobernanza internacional ártica, sino todo lo contrario; así, por ejemplo, la participación de la UE en la OMI no es diferente a la que ostenta con carácter general por el solo hecho de que el tema que tratar sea la navegación por aguas polares. Pero cada uno de estos supuestos - ya sea su participación en la OMI, en el Consejo Ártico, etc.- es una pieza del puzle que termina por componer el perfil de la Unión como actor ártico, y en la medida en que su participación es desigual y asimétrica, su peso se debilita. De ahí el interés por el nivel subregional del Ártico europeo, puesto que, en principio, el margen de actuación y la visibilidad de la Unión son mayores a escala europea, ya no solo en el marco de foros internacionales, sino también por la vía del propio derecho de la Unión.

En la gobernanza ártica internacional el papel principal lo asumen los Estados, cooperando en el marco de diferentes foros, que pueden ser organizaciones internacionales, foros intergubernamentales, procesos de negociación $\mathrm{o}$, incluso, encuentros internacionales para la discusión y/o concertación de posiciones. Por su parte, la UE, aunque es una organización internacional, no es propiamente un foro ártico, sino un actor ártico. Se trata de una situación singular, al ser la única organización internacional que puede ser considerada como actor ártico, y no se ve facilitada ni desde dentro ni desde fuera: los Estados árticos de la Unión reivindican su protagonismo internacional como Estados árticos, fundamentalmente en el marco del Consejo Ártico; y 
la Unión tampoco cuenta con la complicidad de los restantes Estados árticos. Nuevamente, volvemos a señalar que no se trata de un problema exclusivamente ligado a la gobernanza internacional de los asuntos árticos y, sin duda, los avances que con carácter general puedan producirse en la aceptación de la UE en la comunidad jurídica internacional fortalecerán también su posición como actor ártico. Pero esas dificultades que encuentra la Unión con carácter general se ven acentuadas en relación con la gobernanza de asuntos árticos a nivel regional (A8) y del océano Central Ártico (A5) por el celo con el que los Estados árticos reivindican su posición. 